
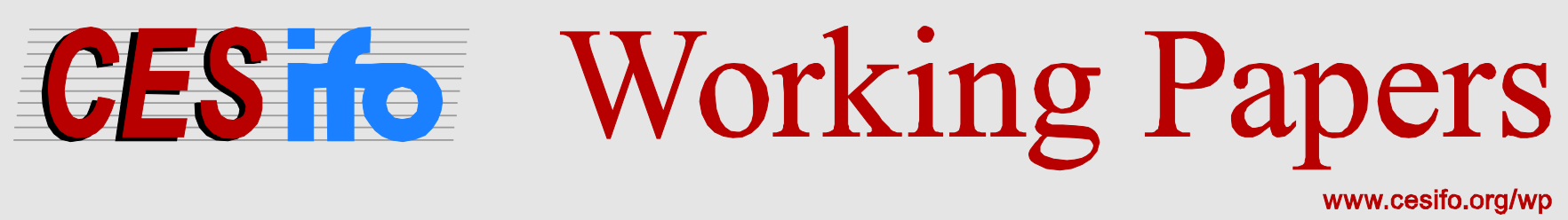

\title{
Optimal Liability when Consumers Mispredict Product Usage
}

\author{
Andrzej Baniak \\ Peter Grajzl
}

\author{
CESIFO WORKING PAPER NO. 5903 \\ CATEGORY 13: BEHAVIOURAL ECONOMICS \\ MAY 2016
}

An electronic version of the paper may be downloaded

- from the SSRN website:

- from the RePEc website:

- from the CESifo website:

wWw.SSRN.com

Www.RePEc.org

www.CESifo-group.org/wp 


\title{
Optimal Liability when Consumers Mispredict Product Usage
}

\begin{abstract}
We contrast alternative liability rules for social control of product risks when heterogeneous consumers considering purchasing a durable good due to cognitive errors and biases mispredict future product benefits and, thus, the extent of future product usage. Since the expected consumer harm directly depends on the level of product usage, the consequences of consumers' mispredictions vary with the prevailing liability regime. We first characterize the consumers' purchasing decision and the equilibrium levels of safety and activity from the product's usage under no liability, strict liability, and negligence rule. We then compare the three legal regimes from the social welfare standpoint. Our analysis clarifies why and how the choice of the socially optimal legal regime depends on the distribution of consumers based on the direction and extent of their mispredictions. When consumers are susceptible to mispredicting future product benefits and usage, the appropriate legal regime is likely product-specific.
\end{abstract}

JEL-Codes: K130, D030, D610.

Keywords: misprediction, activity, durable consumer products, product risk, liability rules.

\author{
Andrzej Baniak \\ Department of Economics \\ Central European University \\ Nador u. 9 \\ Hungary - 1051 Budapest \\ baniaka@ceu.edu
}

\author{
Peter Grajzl* \\ Department of Economics \\ The Williams School of Commerce, \\ Economics, and Politics \\ Washington and Lee University \\ USA - Lexington, VA 24450 \\ grajzlp@wlu.edu
}

*corresponding author

April 12, 2016

For helpful comments and discussion, we thank Amanda Bower, Christopher Bruner, Mark Drumbl, Joshua Fairfield, Brant Hellwig, Botond Köszegi, Bryan McCannon, Victoria Sahani, Christopher Seaman, Rob Straughan, and participants at seminars at Central European University and Washington and Lee University School of Law. 


\section{Introduction}

Liability of manufacturers for harms incurred by their customers (products liability, in short) has been a major area of law and litigation in the U.S., and a body of law growing in scope and prominence worldwide (Polinsky and Shavell 2010). Accordingly, what constitutes an appropriate legal institutional regime for social control of product-related torts has been a subject of extensive policy and scholarly discussion in law and economics (see, e.g., Viscusi 1991, Geistfeld 2009, Polinsky and Shavell 2010, Goldberg and Zipursky 2010, Hylton 2013, Daughety and Reinganum 2013).

In this paper we contribute to this debate by comparing alternative liability rules for the allocation of losses from defective durable consumer products when consumers mispredict the extent of future benefits from, and hence usage of, the product. Given that the extent of product usage directly impacts the magnitude of expected losses from product-related harm (see, e.g., Shavell 1980, Garoupa and Ulen 2013), an understanding of the implications of consumers' misprediction of future product benefits and usage for product safety and for comparative performance of alternative liability regimes constitutes an important, yet thus far unexplored, topic of inquiry.

Consumers mispredict the extent of future product benefits and usage because of cognitive errors and biases. One salient and empirically well-documented behavioral phenomenon that triggers the consumer to either overestimate or underestimate future product benefits and usage is projection bias (Loewenstein et al. 2003), a common cognitive mistake that causes an individual to exaggerate the extent to which his or her future preferences and tastes will resemble his or her current preferences and tastes (see, e.g., Hsee and Hastie 2006, Loewenstein 2000, Wilson and Gilbert 2003, Loewenstein and Schkade 1999, Conlin et al. 2007, 
Kliger and Levy 2008, Simonsohn 2009, Quoidbach and Dunn 2010). When a consumer considering purchasing a durable good is subject to projection bias, he or she is overcome by momentary feelings and, consequently, fails to rationally assess the true future benefits from the product's usage (Loewenstein et al. 2003: Sec V; Busse et al. 2012). For instance, if a potential buyer of a sports car is overwhelmed by the positive emotions associated with the thought of owning the car, he or she will tend to overestimate the extent of the car's true future benefits and usage.

A consumer, however, will mispredict the extent of future product benefits and usage even in the absence of projection bias if the consumer possesses unrealistically positive or negative views about his or her own traits or prospects that are relevant for deriving utility from the product's usage. ${ }^{1}$ An avid climber, for example, might be pessimistic about his or her ability to benefit from a new stationary bike and may hence underestimate the benefits from its usage. In contrast, a person diagnosed with a non-life-threating medical condition such as sleep apnea may feel optimistic about the prospects of improving their wellbeing and may thus overestimate the extent to which they can derive utility from using a continuous positive airway pressure (CPAP) machine. Empirical evidence suggests that overconfidence and overoptimism are indeed ubiquitous with respect to a wide range of behaviors (see, e.g., Moore and Healy 2008, Köszegi 2014, Rabin 1998, Grubb 2009, DellaVigna 2009, Sandroni and Squintani 2013, Fellner-Röhling and Krügel 2014, Brookins et al. 2014, Heidhues et al. 2016). Underconfidence and pessimism

\footnotetext{
${ }^{1}$ Loewenstein et al. (2003: 1233, fn. 28), for example, argue that the empirically documented negative gap between the predicted extent of smoking by high school students who were already heavy smokers and the same individuals' actual extent of smoking, measured at a later point in time, can be explained both by projection bias (heavy smokers might have been in a nicotine-sated state when making the prediction) and overconfidence in the ability to exercise self-control.
} 
are less common, yet when expressed they likewise notably influence economic decision-making and outcomes (see, e.g., Abel 2002, Moore and Healy 2008: 503-504, Heidhues et al. 2016). ${ }^{2}$

To study the consequences of consumers' misprediction of future product benefits and usage for products liability, we develop a model in which consumers consider first purchasing and later using a durable good provided by competitive firms. In our framework, the consumers are heterogeneous with respect to the direction and extent of their misprediction of future product benefits and usage: while some at the time of the purchasing decision overestimate the future benefits from, and thus the extent of future usage of, the product, others underestimate them. Since the expected harm to the consumer ceteris paribus increases with the level of activity stemming from the product's usage (see, e.g., Shavell 1980, Miceli 1997, Cooter and Ulen 2011), the precise impact of consumer mispredictions of future product benefits and usage on the equilibrium level of product safety, price, and the consumers' decisions whether to purchase the product, varies with the liability regime in place.

We first characterize the equilibrium level of safety, the consumers' purchasing decision, and the equilibrium usage of the product under each of the three standard legal regimes: no liability, strict liability, and negligence. We then contrast the three regimes from the social welfare standpoint. The central idea we emphasize is that when consumers are susceptible to misprediction of product benefits and usage, alternative liability rules differ not only with respect to the equilibrium levels of product safety, usage, and price, which in turn determine ex-post net consumer welfare, but, importantly, also with regard to the extent of the market they support.

\footnotetext{
${ }^{2}$ In the context of product purchasing decision, the concept of misprediction of future product benefits and usage resonates with the notion of belief disconfirmation used in the marketing literature to explain consumers' postpurchase satisfaction (see, e.g., Oliver 1977, 1980; Spreng et al. 1996). According to this theory, consumers compare actual performance with a priori expectations about the product. When a product outperforms (underperforms) the person's original expectations, the disconfirmation of beliefs is positive (negative), which is posited to increase (decrease) post-purchase satisfaction.
} 
Under the regime of no liability, consumers bear their own accident losses. Competition induces firms to offer product varieties that maximize ex-ante consumer welfare. Consequently, all consumers purchase the product variety offered to their type as captured by the direction and extent of their respective misprediction of future product benefits and usage. Consumers who significantly mispredict the extent of future product benefits and usage, however, realize relatively low ex-post welfare because their ex-post choice of the level of activity associated with the product notably diverges from the ex-ante anticipated level that determines the level of safety and the price of the purchased product.

Under strict liability, in contrast, the costs of harm in case of a product-related accident are borne solely by the firm. Rational firms anticipate that the consumers will choose excessive ex-post level of activity and offer a correspondingly safe product at a high price regardless of the extent and direction of consumer's mispredictions. Consumers who ex ante significantly underestimate future product benefits and usage under strict liability therefore abstain from purchasing the product in the first place. Consumers that do purchase the product, however, realize ex-post welfare that is independent of the extent of their mispredictions. In comparison with no liability, strict liability therefore leads to lower ex-post welfare for consumers that significantly underestimate future product benefits and usage and higher ex-post welfare for consumers that substantially overestimate future benefits and usage.

Finally, under the negligence regime a firm is liable for consumer losses in case of an accident only if the firm has not met the due standard of precaution. In equilibrium all firms meet the due standard, set at the first-best level of safety, and operate under a de facto no liability regime. Since higher safety comes at a cost of higher price, under negligence, much like under the regime of strict liability, the consumers who significantly underestimate future product 
benefits and usage choose not to purchase the product. We show that the extent of underestimation exhibited by the marginal consumer who still chooses to purchase the product is greater under negligence than under strict liability. In contrast, consumers who moderately underestimate future product benefits and usage under negligence purchase the product and realize first-best ex-post level of welfare which is independent of the extent of their misprediction.

Accordingly, when consumers mispredict the extent of future product benefits and usage, none of the three alternative legal regimes achieves first best and none of the three alternative legal regimes unconditionally dominates the other two. Instead, we demonstrate that the choice of the social-welfare-maximizing legal regime critically depends on the underlying distribution of consumers based on the direction and extent of their misprediction. Social welfare is highest under no liability when consumers tend to significantly underestimate future product benefits and usage; under negligence when consumers moderately underestimate, moderately overestimate, or do not mispredict future product benefits and usage; and under strict liability when consumers significantly overestimate future product benefits and usage. To the extent that the exact form of the distribution of consumers based on their misprediction varies across different categories of durable consumer products, our analysis therefore implies that the appropriate choice of liability regime may be product contingent (see, e.g., Shavell 2004: 219-220). We illustrate this point by providing a suggestive typology of different categories of durable consumer products according to the extent and direction of consumers' misprediction of future product benefits and usage and discuss which of the three legal regimes is likely most suitable for which product category.

Our paper offers a novel set of considerations regarding the functioning of alternative product liability rules examined by the voluminous literature in law and economics (see, e.g., 
Geistfeld 2009, Daughety and Reinganum 2013). While our model builds on Shavell's (1980) original framework, the source of efficiency differences between alternative liability regimes in our framework is not consumers' misperception of product risks as measured by the likelihood of product failure (see, e.g., Shavell 1980, Landes and Posner 1985, Miceli 1997, Polinsky and Shavell 2010, Cooter and Ulen 2011), but rather consumers' misprediction concerning future product benefits and activity associated with the product's usage. To this end, our analysis departs from the canonical model of product liability (Shavell 1980, 2004, 2007; Miceli 1997, Cooter and Ulen 2011) by explicitly emphasizing the sequential nature of consumers' decision concerning purchase and usage of the product, and by stressing the interpretation of activity level (see, e.g., Garoupa and Ulen 2013) as the extent of product usage rather than the output level.

More generally, our paper contributes to the growing body of research on the repercussions of behavioral biases, cognitive errors, and emotions for market outcomes and institutional design (see, e.g., Rabin 1998, DellaVigna 2009, Köszegi 2014, Rick and Loewenstein 2009). The emphasis on behavioral foundations and its consequences has become particularly prominent in considerations about the design of law and legal institutions (see, e.g.,

Jolls et al. 1998, Korobkin and Ulen 2000, Sunstein 2000, Blumenthal 2005, Thaler and Sunstein 2008, Ulen 2014). We add to this literature by analyzing market outcomes and the performance of alternative liability rules when consumers of durable products provided by competitive firms mispredict future product benefits and usage.

\section{The Model}

\subsection{Products, Firms, and Consumers}

We develop a model of torts in the spirit of Shavell (1980) where the potential injurer is a riskneutral firm and the potential victim is a likewise risk-neutral consumer. Consumers are 
considering purchasing and using one unit of a durable good: a household appliance, lawn and garden equipment, consumer electronics, sports good, or even a retail medical device such as the CPAP machine. For simplicity, as in the benchmark model (see, e.g., Shavell 1980, Miceli 1997, Cooter and Ulen 2011), we assume away any possibility for liability waivers, warranty options, and product insurance.

Taking into account the likelihood of a product-caused accident, the expected monetary equivalent of harm that the consumer incurs per unit of activity equals $H(x)>0$, where $x \geq 0$ captures the manufacturer's investment in precaution or, equivalently, the level of product safety provided by the manufacturer. The function $H(\cdot)$ is decreasing and strictly convex, with $H(x) \rightarrow 0$ as $x \rightarrow 0$. Following the standard approach in the literature (see, e.g., Shavell 1980, Miceli 1997, Nussim and Tabbach 2009), we let the total expected harm incurred by the consumer be linear in the level of activity and equal $a \cdot H(x)$, where $a \geq 0$ denotes the level of consumer's activity, that is, the extent of the product's usage as measured, for example, by the number of days or hours that the consumer has used the product. ${ }^{3}$

The products are manufactured and supplied by identical competitive firms. As in Shavell (1980: 13), we let each firm's cost of producing one unit of output equal $C(x)$, where the function $C(\cdot)$ is strictly increasing, convex, and $C(x) \rightarrow \infty$ as $x \rightarrow \infty$. With each firm supplying exactly one unit of the product, firm's expected profit equals $p-C(x)-(1-\gamma) a H(x)$, where $p$ is the product's price and $(1-\gamma) a H(x)$ is the firm's expected liability payment given the legal regime captured by $\gamma \in[0,1]$. For example, $\gamma=1$ under the regime of no liability and $\gamma=0$ under the regime of strict liability with full compensation (see below).

\footnotetext{
${ }^{3}$ As in the benchmark model (see, e.g., Shavell 1980, Miceli 1997, Nussim and Tabbach 2009, Cooter and Ulen 2011), we thus assume away any scale effects in the activity level.
} 
The distinctive feature of our model is that we allow for the possibility that, due to cognitive errors and biases discussed in the previous section, the consumers mispredict the extent of future product benefits from the product's usage. To this end, we distinguish between the consumer's ex-ante predicted gross benefit from using the product, as assessed prior to the product's purchase, and the consumer's ex-post realized gross benefit from the product's usage, as assessed after the purchase. We denote the former with the twice continuously differentiable function $B(a, \alpha)$ and the latter with $B(a, 1) \equiv B(a)$. The parameter $\alpha>0$ captures the extent and direction of the consumer's misprediction of future benefits from the product. When $\alpha=1$, the consumer's perceived gross benefits schedule from the product prior to the product's purchase coincides with the consumer's gross benefits schedule from the product after the purchase. When $\alpha=1$, the consumer therefore correctly predicts the future benefits from the product. Whenever $\alpha \neq 1$, however, $B(a, \alpha)$ differs from $B(a)$ and, thus, the consumer mispredicts the future benefits from the product's usage. The firms understand that the consumers might mispredict future product benefits and therefore recognize the consumer's type as captured by $\alpha .{ }^{4}$

We assume that both the consumer's perceived future total benefit and perceived future marginal benefit from using the product, as evaluated prior to the product's purchase, increases with $\alpha$ :

$$
\begin{gathered}
\frac{\partial B(a, \alpha)}{\partial \alpha}>0 \\
\frac{\partial^{2} B(a, \alpha)}{\partial \alpha \partial a}>0
\end{gathered}
$$

\footnotetext{
${ }^{4}$ Because firms are operating in a perfectly competitive environment, none of our analysis would change if we instead assumed that $\alpha$ is consumer's private information. The reason is that under perfect competition among firms and when the consumer type does not directly enter the firm's profit function (private values), "adverse selection does not change the set of competitive equilibria" relative to the full information scenario and is, in this sense, "irrelevant" (Salanie 2005: 59).
} 
for all $a$ and $\alpha$. We further assume that for a given $\alpha, B(a, \alpha)$ is strictly concave and singlepeaked in $a$, with $B(0, \alpha)=0$, and $B(a, \alpha) \rightarrow \infty$ and $\partial B(a, \alpha) / \partial a \rightarrow \infty$ as $\alpha \rightarrow \infty$ for any given $a$. We denote $\hat{a}(\alpha)=\operatorname{argmax}_{a} B(a, \alpha)$ such that $\hat{a}(\alpha) \rightarrow 0$ and, hence, $B(\hat{a}(\alpha), \alpha) \rightarrow 0$ as $\alpha \rightarrow 0$ and $\hat{a}(\alpha) \rightarrow \infty$ as $\alpha \rightarrow \infty .{ }^{5}$ The above assumptions imply that $\hat{a}(\alpha)$ and $B(\hat{a}(\alpha), \alpha)$ are increasing in $\alpha$ : relative to consumers with a low perceived future benefit from the product's usage, consumers with a high perceived future benefit ex ante believe that they will use the product more as well as realize a higher gross benefit. Therefore, when $\alpha>1$, the consumer ex ante overestimates the ex-post benefits from, and the extent of, the product's usage. In contrast, when $\alpha<1$, the consumer ex ante underestimates the ex-post benefits from, and the extent of, the product's usage. Figure 1 illustrates these assumptions and portrays the relationship between $B(a, \alpha)$ and $B(a)$ for different values of $\alpha$.

For a given risky product, different consumers will be characterized by different values of $\alpha$. Consider the example of a treadmill. A recreational fitness enthusiast who has decided to make good on their New Year's resolution to commence a more rigorous exercise regime after having been exposed to an appealing treadmill advertisement might overestimate the benefits from using the treadmill. In contrast, an individual who severely dislikes exercising, but whose doctor has urged them to begin a workout regime in order to significantly reduce body weight, might ex ante underestimate the ex-post benefits from using the same treadmill. Accordingly, let $f(\alpha)$ be the density function and $F(\alpha)$ the corresponding cumulative distribution function describing the distribution of consumers for $\alpha>0$.

To the extent that there is an association between product categories and consumer's predominant emotional state at the time of the purchase of the product, different categories of

\footnotetext{
${ }^{5}$ A simple quadratic functional form such as $B(a, \alpha)=-a^{2}+2 \alpha a$ satisfies all of these assumptions.
} 
risky products are conceivably characterized by different distributions of $\alpha$. For example, the purchase of a sports car typically evokes exuberance and, hence, the modal consumer likely overestimates future product benefits and usage. In contrast, when making purchasing decisions about certain retail medical equipment, consumers are often under emotional distress and, therefore, the modal consumer quite plausibly underestimates the extent of future product benefits and usage. We return to the discussion about the relationship between product categories and distribution of $\alpha$ in Section 4 below.

\subsection{Social Welfare and First-Best}

The consumers are identical in all but one respect: the direction and extent of their misprediction of future product benefits and usage as captured by $\alpha$. Accordingly, the ex-post social welfare when all consumers purchase and use the product equals

$$
\Omega(x, a)=\int_{0}^{\infty}[B(a)-a H(x)-C(x)] f(\alpha) d \alpha=B(a)-a H(x)-C(x) .
$$

Assuming an interior solution, the following characterizes the socially optimal product safety and activity levels:

$$
\begin{gathered}
B^{\prime}(a)-H(x)=0 \\
-a H^{\prime}(x)-C^{\prime}(x)=0
\end{gathered}
$$

Expression (4) implies that at the social optimum, the marginal benefit to the consumer from an additional unit of activity should equal the marginal cost as measured by higher expected damage payments. Expression (5) implies that the marginal benefit of greater safety, as measured by lower expected damage payments, should equal the marginal cost of providing safety. (4) and (5) together determine the first-best level of safety $x^{F B}$ and activity $a^{F B}$, as illustrated in Figure 2 . The function $a^{*}(x)$ in Figure 2 is defined by (4) and shows the socially optimal level of activity 
for a given level of product safety. The function $x^{*}(a)$ is defined by (5) and portrays the socially optimal level of product safety for a given level of activity. ${ }^{6}$ Thus, $a^{F B}=a^{*}\left(x^{F B}\right)$ and $x^{*}\left(a^{F B}\right)=x^{F B}$. We assume that the second-order conditions are satisfied and, moreover, that it is always socially beneficial to produce, sell, and consume the risky product:

$$
\Omega\left(x^{F B}, a^{F B}\right) \equiv \Omega^{F B}=B\left(a^{F B}\right)-a^{F B} H\left(x^{F B}\right)-C\left(x^{F B}\right)>0 .
$$

In our model, the first-best precaution and activity levels are therefore determined simultaneously. This differentiates our framework from the conventional approach (see, e.g., Shavell 1980, 2004, 2007; Miceli 1997) based on Shavell's (1980) original analysis. Specifically, in the conventional model, precaution and activity, where the latter is interpreted as output, are both chosen by the potential injurer (firm) and the total costs of precaution are assumed to be proportional to the (firm's) level of activity (output). These assumptions imply that in the conventional framework the first-best level of precaution is independent of activity (see Shavell 1980, 2004, 2007; Miceli 1997). In this sense, our setting resonates with Nussim and Tabbach's (2009) model of accidents in which there is no contractual relationship between the relevant parties but where the potential injurer's precaution is 'durable' in that the cost of precaution is independent of the injurer's activity level.

\section{Equilibrium under Different Legal Regimes}

The canonical unilateral-precautions model when the injurers are firms and the victims are customers implicitly assumes that the decision about the activity level (output) occurs at the time of the purchasing decision (see, e.g., Shavell 1980, 2004, 2007; Miceli 1997, Cooter and Ulen 2011, Daughety and Reinganum 2013). To highlight the consequences of consumers' mispredictions of future product benefits and usage for the effectiveness of different liability

\footnotetext{
${ }^{6}$ The relative slopes of the functions $x^{*}(a)$ and $a^{*}(x)$ portrayed in Figure 2 are implied by the second-order sufficient conditions. See Appendix A.
} 
rules, we depart from this assumption and assume instead that the act of the product's purchase precedes the usage of the product. The assumption that the purchasing decision precedes the usage decision is particularly applicable in the context of durable goods: a consumer typically considers purchasing one unit only of a specific durable good (a toaster, lawn mower, treadmill, or CPAP machine), and then, conditional on the product's purchase, uses the product on multiple occasions and often over a prolonged period of time. We therefore postulate the following timing of events.

In period 1, the firm chooses safety level $x$ and proposes price $p$. Having observed $x$ and $p$, the consumer decides whether to purchase the product or not. The consumer's decision is based on the consumer's period-one net utility, expressed in monetary terms, from purchasing the product, $U_{1}(a, \alpha)$, which in turn depends on the ex-ante perceived benefit from the future use of the product, $B(a, \alpha){ }^{7}$ As we clarify below, the precise form of $U_{1}(a, \alpha)$ depends on the prevailing legal regime that determines which party (the consumer or the firm) is liable for any productrelated damages. The consumer therefore first determines her ex-ante optimal activity level $a_{1}$ defined as the level of activity $a$ that maximizes $U_{1}(a, \alpha)$. Upon establishing $a_{1}$, the consumer purchases the product if and only if $U_{1}\left(a_{1}, \alpha\right)$ exceeds net consumer utility when the consumer does not purchase the product, the value of which we normalize to equal zero.

Providing that the consumer purchased the product in period 1, in period 2 the consumer chooses her ex-post activity level to maximize the ex-post net utility $U_{2}(a, \alpha)$, which takes into account the ex-post benefit from the product, $B(a) . U_{2}(a, \alpha)$ thus depends on $\alpha$ indirectly through product price and safety level determined in period 1. Denoting the consumer's corresponding

\footnotetext{
${ }^{7}$ The approach whereby utility is expressed in terms of its monetary equivalent is standard in the literature (see, e.g., Shavell 1980, Miceli 1997) and comes without loss of generality since the setup could also be reinterpreted as one where the consumer has quasilinear preferences over the product in question and all other goods.
} 
ex-post optimal activity as $a_{2}$, the consumer then realizes ex-post utility equal to $U_{2}\left(a_{2}, \alpha\right)$. For simplicity and to highlight the consequences of consumer's misprediction of future product benefits, we do not discount period 2 payoffs due to passage of time per se.

\subsection{No Liability}

Under no liability, the producer's expected liability payment is zero, and thus the product price equals $p^{N L}(x)=C(x)$. The consumer's ex-ante net utility equals $U_{1}^{N L}(a, x, \alpha)=B(a, \alpha)-C(x)-a H(x)$. Competition induces firms to offer the level of product safety $x$ which maximizes the consumer's ex-ante utility. At the same time, the consumer contemplating purchase of the product chooses the ex-ante level of activity that maximizes her ex-ante net utility. Consequently, in a no liability equilibrium,

$$
\begin{gathered}
\frac{\partial B(a, \alpha)}{\partial a}-H(x)=0 \\
-a H^{\prime}(x)-C^{\prime}(x)=0 .
\end{gathered}
$$

Denote the solution to the system (7) and (8) above as $\left(a_{1}{ }^{N L}(\alpha), x^{N L}(\alpha)\right)$. The equilibrium level of product safety and ex-ante activity under no liability then both increase with $\alpha$ : $a_{1}{ }^{N L^{\prime}}(\alpha)>0$ and $x^{N L \prime}(\alpha)>0$ (see Appendix A). Note that $\left(a_{1}{ }^{N L}(1), x^{N L}(1)\right)=\left(a^{F B}, x^{F B}\right)$. Thus, when $\alpha>1, x^{N L}(\alpha)>x^{F B}$ and $a_{1}{ }^{N L}(\alpha)>a^{F B}$. In contrast, when $\alpha<1, x^{N L}(\alpha)<x^{F B}$ and $a_{1}{ }^{N L}(\alpha)<a^{F B}$. Figure 2 illustrates the no liability equilibrium for different values of $\alpha$. The equilibrium price under no liability equals $p^{N L}(\alpha)=C\left(x^{N L}(\alpha)\right)$ and increases in $\alpha$.

Therefore, whenever the consumers mispredict future product benefits and usage $(\alpha \neq 1)$, the equilibrium safety and ex-ante activity level under no liability differ from the first best. When the consumers overestimate the future benefits from the product, no liability leads to excessive ex-ante anticipated activity levels as consumers anticipate to use the product extensively. 
Consequently, in order to mitigate their expected losses from product-caused harm, the consumers demand an excessively high level of product safety and are willing to pay a high product price for it. In contrast, when the consumers underestimate the future benefits from the product, no liability leads to too low ex-ante anticipated activity levels. Accordingly, the consumers demand an excessively low level of product safety for which they are willing to pay only a relatively low product price. The extent to which ex-ante activity and safety exceed (fall short of) the corresponding first-best levels increases with the degree to which the consumers overestimate (underestimate) the future benefits from the product.

The consumer's maximized ex-ante utility equals

$$
U_{1}{ }^{N L}(\alpha)=B\left(a_{1}{ }^{N L}(\alpha), \alpha\right)-C\left(x^{N L}(\alpha)\right)-a_{1}{ }^{N L}(\alpha) H\left(x^{N L}(\alpha)\right) .
$$

Lemma 1: $U_{1}{ }^{N L}(\alpha)$ is increasing for all $\alpha>0$. Furthermore, $U_{1}{ }^{N L}(\alpha) \rightarrow 0$ as $\alpha \rightarrow 0$.

The function $U_{1}{ }^{N L}(\alpha)$ is illustrated in Figure 3. Since competition leads to the maximization of consumer's ex-ante net utility, under no liability, all consumers, regardless of the value of their $\alpha$, choose to purchase the product.

Consider, next, the consumer's decision in period 2. Having purchased the product with safety level $x^{N L}(\alpha)$ at price $p^{N L}(\alpha)$, the consumer of type $\alpha$ chooses the ex-post activity level to maximize $B(a)-p^{N L}(\alpha)-a H\left(x^{N L}(\alpha)\right)$. With $p^{N L}(\alpha)=C\left(x^{N L}(\alpha)\right)$, expression (4) and subsequent discussion imply that the resulting ex-post activity level equals $a_{2}{ }^{N L}(\alpha)=a^{*}\left(x^{N L}(\alpha)\right)$. Given that the function $a^{*}(\cdot)$ is strictly increasing (see Figure 2) and $a_{2}{ }^{N L}(1)=a^{*}\left(x^{N L}(1)\right)=a^{*}\left(x^{F B}\right)=a^{F B}$, it follows that $a_{2}{ }^{N L}(\alpha)>a^{F B}$ when $\alpha>1$ and $a_{2}{ }^{N L}(\alpha)<a^{F B}$ when $\alpha<1$. Furthermore, for given $\alpha>1$, $a_{2}{ }^{N L}(\alpha)<a_{1}{ }^{N L}(\alpha)$ and for given $\alpha<1, a_{2}{ }^{N L}(\alpha)>a_{1}{ }^{N L}(\alpha)$, as illustrated in Figure 2.

That is, under no liability the consumers who overestimate future product benefits and usage ex post adjust their ex-ante choice of activity downward. Due to the purchase of a product 
with an excessively high levels of safety, however, the ex-post choice of activity level for consumers with $\alpha>1$ still exceeds the first-best level. Similarly, those consumers who ex ante underestimate future product benefits and usage ex post adjust their ex-ante choice of activity upward. Yet because they purchased a product with an excessively low level of safety, the expost choice of activity level for consumers with $\alpha<1$ nevertheless falls short of the first-best level.

The consumer's maximized ex-post net utility under no liability then equals

$$
U_{2}{ }^{N L}(\alpha)=B\left(a^{*}\left(x^{N L}(\alpha)\right)-C\left(x^{N L}(\alpha)\right)-a^{*}\left(x^{N L}(\alpha)\right) H\left(x^{N L}(\alpha)\right) .\right.
$$

The following result establishes the properties of $U_{2}{ }^{N L}(\alpha)$.

Lemma 2: $U_{2}{ }^{N L}(\alpha)$ is increasing for $\alpha<1$, attains positive value at $\alpha=1$, and is decreasing for $\alpha>1$ with $U_{2}{ }^{N L}(\alpha)<0$ as $\alpha \rightarrow \infty$. Furthermore, $U_{1}{ }^{N L}(\alpha)<U_{2}{ }^{N L}(\alpha)$ if $\alpha<1, U_{1}{ }^{N L}(\alpha)=U_{2}{ }^{N L}(\alpha)$ if $\alpha=1$, and $U_{1}{ }^{N L}(\alpha)>U_{2}{ }^{N L}(\alpha)$ if $\alpha>1$.

Lemma 2 is illustrated in Figure 3. Maximized ex-post net utility under no liability decreases with the extent of consumer misprediction of future product benefits (i.e. as $\alpha$ diverges from the value one in either direction). The reason is that the larger the extent of misprediction, the more the level of product safety for the purchased product diverges from the optimal (i.e. net consumer utility-maximizing) level of safety in the absence of misprediction $\left(x^{F B}\right)$ and thus the more also the ex-post level of activity diverges from the optimal level of activity in the absence of misprediction $\left(a^{F B}\right)$; see Figure 2. Consequently, consumers who ex ante underestimate future benefits from the product ex post experience an increase in their net utility. Ex post (after purchasing the product), these consumers realize that the benefits from the product's usage are higher than anticipated. Accordingly, the consumers increase their level of activity, which in turn increases their ex-post net utility relative to their ex-ante anticipated level. In contrast, consumers who ex ante overestimate future benefits from the product ex post realize that the benefits from 
the product's usage are lower than anticipated. Hence, these consumers decrease their level of activity below the ex-ante level, which in turn decreases their ex-post net utility below their exante anticipated level.

In sum, under no liability firms offer a continuum of products. Consumers of type $\alpha$ are offered product variety characterized by safety level $x^{N L}(\alpha)$ at price $p^{N L}(\alpha)=C\left(x^{N L}(\alpha)\right)$, where $x^{N L}(\alpha)$ is defined by (7) and (8). All consumers purchase the respective product variety offered to them. Ex post, the consumer of type $\alpha$ realizes net utility defined in (10). With firms earning zero profits, social welfare under no liability thus equals

$$
\Omega^{N L}=\int_{0}^{\infty} U_{2}^{N L}(\alpha) f(\alpha) d \alpha .
$$

\subsection{Strict Liability}

Under strict liability with full compensation, the firm's marginal cost is $C(x)+a H(x)$ which in turn equals product price $p^{S L}$. Because the firms cannot control the consumer's activity level, they cannot condition the price on activity. Instead, when choosing the level of precaution and determining the price in period 1 , the firms must predict the consumers' future level of activity. Under strict liability consumers are not liable in the event of a product-related accident and will therefore engage in moral hazard. Firms understand this and know that in period 2, after purchasing the product, the consumers will choose the level of activity equal to $\hat{a}=\operatorname{argmax} a\left\{B(a)-p^{S L}\right\}$, where $\hat{a}>a^{F B}$ (see expression (4)). Rational firms in period 1 therefore correctly predict the consumers' ex-post level of activity $\hat{a}$. Competitive pressure then incentivizes firms to choose the level of activity $x$ such that each firm's marginal costs, $C(x)+\hat{a} H(x)$, are minimized. Thus, $x^{S L}=x^{*}(\hat{a})$, where the function $x^{*}(\cdot)$ is defined by (5). Because $x^{*}(\cdot)$ is increasing, $\hat{a}>a^{F B}$ implies that $x^{S L}=\chi^{*}(\hat{a})>x^{F B}$ (see Figure 2): under strict liability, firms 
anticipate excessively high levels of activity and choose excessively high levels of precaution. The product's price then equals $p^{S L}=C\left(x^{S L}\right)+a^{S L} H\left(x^{S L}\right)=C\left(x^{*}(\hat{a})\right)+\hat{a} H\left(x^{*}(\hat{a})\right)$.

Note that since $x^{*}(\hat{a})>x^{N L}(\alpha)$ for $\alpha \leq 1$ and $p^{N L}(\alpha)=C\left(x^{N L}(\alpha)\right)$, we have $p^{S L}>p^{N L}(\alpha)$ for products offered to consumers who either underestimate or do not mispredict future product benefits. In the case of products offered to consumers who grossly overestimate future product benefits ( $\alpha$ sufficiently greater than 1$)$, however, the equilibrium level of precaution under no liability can significantly exceed the equilibrium level of precaution under strict liability, and thus the product's price under no liability can exceed the product's price under strict liability $\left(p^{S L}<p^{N L}(\alpha)\right)$.

Facing safety level $x^{S L}$ and price $p^{S L}$, the consumer in period 1 chooses ex-ante activity level $a_{1}{ }^{S L}(\alpha)=\operatorname{argmax} a\left\{B(a, \alpha)-p^{S L}\right\}=\operatorname{argmax}_{a} B(a, \alpha)=\hat{a}(\alpha)$, which is increasing in $\alpha$. The consumer's maximized ex-ante net utility under strict liability then equals

$$
U_{1}^{S L}(\alpha)=B\left(a_{1}{ }^{S L}(\alpha), \alpha\right)-p^{S L}=B(\hat{a}(\alpha), \alpha)-C\left(x^{*}(\hat{a})\right)-\hat{a} H\left(x^{*}(\hat{a})\right) .
$$

We assume without loss of generality that the consumers who do not mispredict future product benefits under strict liability always purchase the product: $U_{1}{ }^{S L}(1)>0 .{ }^{8}$ The following result then establishes the properties of $U_{1}{ }^{S L}(\alpha)$.

Lemma 3: $U_{1}{ }^{S L}(\alpha)$ is increasing in $\alpha$. $U_{1}{ }^{S L}(\alpha)>0$ for all $\alpha>1$ as well as for values of $\alpha$ smaller than, but still sufficiently close to, 1 . Furthermore, there exists $\alpha_{0}{ }^{S L} \in(0,1)$ such that $U_{1}{ }^{S L}(\alpha)<0$ for all $\alpha<\alpha_{0}{ }^{S L}, U_{1}{ }^{S L}\left(\alpha_{0}{ }^{S L}\right)=0$, and $U_{1}{ }^{S L}(\alpha)>0$ for all $\alpha>\alpha_{0}{ }^{S L}$.

Under strict liability, consumers who significantly underestimate future product benefits and usage $\left(\alpha<\alpha_{0}{ }^{S L}\right)$ realize negative ex-ante net utility and thus abstain from purchasing the

\footnotetext{
${ }^{8}$ None of our qualitative conclusions concerning the relative social desirability of strict liability change if we instead let $U_{1}{ }^{S L}(1)<0$.
} 
product. All other consumers, however, purchase the product. The function $U_{1} S L(\alpha)$ is illustrated in Figure 3. (Lemma 4 establishes the relative position of $U_{1}^{S L}(\alpha)$ vis-à-vis $U_{1}{ }^{N L}(\alpha)$ in Figure 3.)

In period 2, consumers who purchased the product choose ex-post activity level to maximize $B(a)-p^{S L}$. Thus, $a_{2}{ }^{S L}=\hat{a}$ and the maximized ex-post net utility for consumer of type $\alpha$ equals

$$
U_{2}^{S L}(\alpha)= \begin{cases}0 & \text { if } \alpha<\alpha_{0}^{S L} \\ B(\hat{a})-C\left(x^{*}(\hat{a})\right)-\hat{a} H\left(x^{*}(\hat{a})\right) & \text { if } \alpha \geq \alpha_{0}^{S L}\end{cases}
$$

where $U_{2}{ }^{S L}(\alpha)$ for $\alpha \geq \alpha_{0}{ }^{S L}$ is independent of $\alpha$. Hence, we write $U_{2}{ }^{S L}(\alpha)=U_{2}{ }^{S L}$ for $\alpha \geq \alpha_{0}{ }^{S L}$. From (12) and (13), observe that $U_{2}{ }^{S L}=U_{1}{ }^{S L}(1)$, and from (6), $U_{2}{ }^{S L}<\Omega^{F B}$. Figure 3 illustrates the relationship between the consumer's maximized ex-ante and ex-post net utility under strict liability. Under strict liability, all consumers who end up purchasing the product ex post enjoy a positive net utility. Furthermore, consumers who ex ante underestimate the future benefits from the product, but still purchase the product, ex post enjoy an increase in their net utility. These consumers ex post realize that the benefits from the product's usage are greater than anticipated and, hence, increase their ex-post activity and net utility above their respective ex-ante anticipated levels. In contrast, consumers who ex ante overestimate the future benefits from the product, ex post experience a decrease in their net utility. These consumers ex post realize that the marginal and total benefit from the product's usage are lower than they had anticipated. They accordingly reduce their ex-post activity level below the ex-ante chosen level, which in turn decreases their ex-post net utility below the ex-ante anticipated level.

In sum, under strict liability all consumers, regardless of their $\alpha$, are offered the same

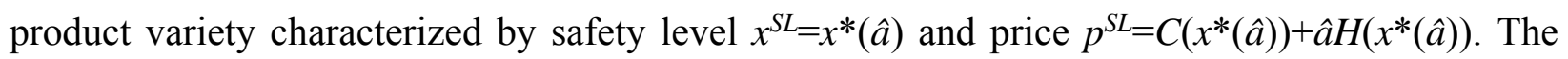
lack of product variety under strict liability is a direct consequence of consumers' incentives to 
engage in moral hazard. Only consumers with $\alpha>\alpha_{0}{ }^{S L}$ purchase the product. Consumers of type $\alpha$ that purchase the product ex post realize net utility equal to $U_{2}{ }^{S L}(\alpha)$. Social welfare under strict liability then equals

$$
\Omega^{S L}=\int_{\alpha_{0}^{S L}}^{\infty} U_{2}^{S L} f(\alpha) d \alpha=U_{2}^{S L}\left[1-F\left(\alpha_{0}^{S L}\right)\right]
$$

\subsection{Negligence}

We follow the standard approach in the literature and assume that activity is, by definition, excluded from the negligence standard due to the prohibitively high costs of acquiring information about activity levels (see, e.g., Shavell 1980, Cooter and Ulen 2011, Landes and Posner 1985, Miceli 1997, Nussim and Tabbach 2009). ${ }^{9}$ Thus, courts must specify a single safety standard $x^{N G}$ that is independent of activity level. Then, if the firm has met the due standard $\left(x \geq x^{N G}\right)$, the firm is not liable in the event of an accident, as is the case under the regime of no liability. In contrast, if the firm has not satisfied the due standard $\left(x<x^{N G}\right)$, strict liability rule applies and the firm is fully liable in case of an accident.

How might the courts determine precaution standard $x^{N G}$ ? A commonly cited legal principle for setting the due standard of precaution is the 'Learned Hand rule' based on which the negligence standard should be set to minimize the sum of precaution costs and expected accident losses (see, e.g., Brown 1973: 331-335; Polinsky and Rogerson 1983: 583; Cooter and Ulen 2011). ${ }^{10} x^{N G}$ must therefore satisfy expression (5). Expected accident-caused losses in our

\footnotetext{
${ }^{9}$ See, however, Ulen and Garoupa (2013) for a critical discussion of this approach.

${ }^{10}$ Geistfeld (2009: 367-368), for example, notes that both the risk-utility test and the consumer expectations test, used by U.S. courts to ascertain liability in the case of product design defects, are often effectively applied as a costbenefit test implied by the Hand rule. The Restatement (Third) of Torts: Products Liability states that "the [riskutility] test is whether a reasonable alternative design would, at reasonable cost, have reduced the foreseeable risks of harm posed by the product" (American Law Institute, 1997: 19). Similarly, "[a] reasonable consumer expects that sellers would reduce product risks in the most cost-effective manner" (Geistfeld 2009: 368). For an illuminating discussion of the cost-benefit analysis in establishing negligence and liability, see Calabresi and Klevorick (1988) and Simons (2008).
} 
context depend on activity level. Thus, in order to pin down the precaution standard the courts must form an estimate of consumers' ex-post activity level. When the firms abide to the negligence standard, the ex-post activity level satisfies expression (4). Taking this into account, the application of Hand's rule in our context therefore implies that the courts set $x^{N G}=\chi^{F B}$.

Three comments concerning the above negligence standard are in place. First, in order to ascertain the precaution standard the courts must know the schedule of precaution costs, the schedule of expected harm, and the schedule of ex-post benefits from the product. That courts possess an understanding of the first two items is considered evident and is invoked routinely in analyses of the negligence regime (see, e.g., Shavell 1980, Miceli 1997, Cooter and Ulen 2011). We argue that the courts are likewise able to obtain knowledge about the third item. Importantly, an understanding of the schedule of ex-post benefits from the product does not imply that the courts observe actual activity levels.

Second, setting $x^{N G}=\chi^{F B}$ in practice requires the courts to reason through a simultaneous system as defined by expressions (4) and (5). Give that legislators and judges alike are susceptible to committing errors (see, e.g., Shavell 2007: 160-161; Cooter and Ulen 2011), the choice of the negligence standard might in practice occasionally deviate from $x^{F B}$. We discuss this possibility in Appendix B and demonstrate that as long as the error in the setting of the negligence standard is relatively small, it exhibits only a negligible effect on the relative social desirability of the negligence rule vis-à-vis strict liability or no liability rule.

Third, the application of Hand's rule in our context entails that the courts focus on ex-post activity and thereby ignore the potential impact of the due standard of precaution on consumers' purchasing decision. This is a reasonable assumption since the consumer's purchasing decision depends on his or her extent and direction of misprediction of future product benefits and usage, 
as captured by $\alpha$, and it is very unlikely that the courts would be knowledgeable about the extent and direction of consumers' mispredictions. In Appendix B we also characterize the socialwelfare-maximizing precaution standard that takes into account the distribution of $\alpha$ and thus the effect on consumers' purchasing decision. We demonstrate that such a standard should in general be set lower than $x^{F B}$. However, because its determination rests on an untenable assumptions that the courts know the exact distribution of $\alpha$ and, furthermore, that the courts are willing and able to redefine the due standard of precaution following any change in the distribution of $\alpha$, this kind of standard is unlikely to be applicable in adjudicatory practice.

We, therefore, proceed with the analysis of firm and consumer behavior under the assumption that $x^{N G}=\chi^{F B}$ under the negligence rule. We first examine firms' incentives to satisfy or violate a given due standard of precaution $x^{N G}=\chi^{F B}$. Since $x^{N L}(\alpha)$ is increasing in $\alpha$ (see Section 3.1 and Appendix A) and $x^{N L}(1)=\chi^{F B}$, the firms serving consumers of type $\alpha \geq 1$ always optimally choose to satisfy the due standard of precaution and operate under a de facto no liability regime. Thus, whenever $\alpha \geq 1$, the consumers under the negligence rule choose the exante level of activity equal to the ex-ante level of activity chosen under the no liability rule (see Section 3.1): $a_{1}{ }^{N G}(\alpha)=a_{1}{ }^{N L}(\alpha) \geq a^{F B}$.

Consider, next, a firm that serves consumers from whom $\alpha<1$. Suppose that such a firm violates the negligence standard and chooses $x^{\prime}<x^{F B}$. Then, the firm is subject to strict liability rule, in which case (see Section 3.2) the firm would optimally choose $x^{S L=X^{*}}(\hat{a})>x^{F B}$. This contradicts the original supposition that the firm violates the negligence standard. Furthermore, the firm that offers a product with safety level $x^{\prime}<x^{F B}$ charges price equal to $C\left(x^{\prime}\right)+\hat{a} H\left(x^{\prime}\right)$. Then, a competitor offers a product with safety level $x^{\prime \prime}$ such that $x^{\prime \prime}>x^{\prime}$ and $x^{\prime \prime}<x^{F B}$ at price $C\left(x^{\prime \prime}\right)+\hat{a} H\left(x^{\prime \prime}\right)<C\left(x^{\prime}\right)+\hat{a} H\left(x^{\prime}\right)$, where the last inequality follows from the fact that 
$x^{\prime}<x^{\prime \prime}<x^{F B}<x^{*}(\hat{a})=\operatorname{argmin}_{x}\{C(x)+\hat{a} H(x)\}$. Another competitor then offers a product with safety level $x^{\prime \prime \prime}$ such that $x^{\prime \prime \prime}>x^{\prime \prime}$ and $x^{\prime \prime \prime}<x^{F B}$ at price $C\left(x^{\prime \prime \prime}\right)+\hat{a} H\left(x^{\prime \prime \prime}\right)<C\left(x^{\prime \prime}\right)+\hat{a} H\left(x^{\prime \prime}\right)$, and so on. Hence, any choice of precaution $x$ such that $x<x^{F B}$ is not an equilibrium. Finally, firms serving consumers with $\alpha<1$ will never offer a level of safety above the due standard since consumers with $\alpha<1$ prefer safety level equal to $x^{F B}$ to safety level $x>x^{F B}$ (see Appendix A). It follows that in equilibrium under the negligence rule, the firms serving consumers with $\alpha<1$ satisfy the negligence standard by choosing $x^{N G}(\alpha)=\chi^{F B}$ and set the price equal to $p^{N G}=C\left(x^{F B}\right)$ for all $\alpha<1$, where $p^{N L}(\alpha)<p^{N G}<p^{S L}$ for all $\alpha<1$ (see Appendix A).

Accordingly, when $\alpha<1$, the consumer's ex-ante choice of activity level equals $a_{1}{ }^{N G}(\alpha)=\operatorname{argmax} a\left\{B(a, \alpha)-C\left(x^{F B}\right)-a H\left(x^{F B}\right)\right\}$, where $a_{1}{ }^{N G}(\alpha)$ is increasing in $\alpha$ and satisfies $a_{1}{ }^{N L}(\alpha)<a_{1}{ }^{N G}(\alpha)<a_{1}{ }^{S L}(\alpha)$ (see Appendix A). When $\alpha<1$, the ex-ante choice of activity level under negligence exceeds that under no liability and falls short of that under strict liability because the consumer's marginal costs from additional activity (expected losses per unit of activity) are greater under no liability than under negligence (since $x^{N L}(\alpha)<x^{F B}=x^{N G}(\alpha)$ ) and are equal zero under strict liability.

The consumer's maximized ex-ante net utility under negligence therefore equals

$$
U_{1}^{N G}(\alpha)= \begin{cases}B\left(a_{1}^{N G}(\alpha), \alpha\right)-C\left(x^{F B}\right)-a_{1}^{N G}(\alpha) H\left(x^{F B}\right) & \text { if } \alpha<1 \\ U_{1}^{N L}(\alpha) & \text { if } \alpha \geq 1,\end{cases}
$$

where $U_{1}{ }^{N L}(\alpha)$ is defined in (9). The following result summarizes the properties of the function $U_{1}{ }^{N G}(\alpha)$, illustrated in Figure 3.

Lemma 4: $U_{1}{ }^{N G}(\alpha)$ is increasing for all $\alpha>0$, with $U_{1}{ }^{S L}(\alpha)<U_{1}{ }^{N G}(\alpha)<U_{1}{ }^{N L}(\alpha)$ for all $\alpha<1$. Furthermore, there exists $\alpha_{0}{ }^{N G} \in\left(0, \alpha_{0}{ }^{S L}\right)$ such that $U_{1}{ }^{N G}(\alpha)<0$ for $\alpha<\alpha_{0}{ }^{N G}, U_{1}{ }^{N G}\left(\alpha_{0}{ }^{N G}\right)=0$, and $U_{1}^{N G}(\alpha)>0$ for $\alpha>\alpha 0^{N G}$. 
Under the negligence rule, therefore, consumers who significantly underestimate the expost benefits from the product $\left(\alpha<\alpha_{0}{ }^{N G}\right)$ abstain from purchasing the product and all other consumers purchase the product. The threshold value of $\alpha$ such that the marginal consumer under the negligence rule just purchases the product is smaller than the corresponding threshold value under the strict liability rule. Thus, some consumers (those with $\alpha \in\left(\alpha_{0}{ }^{N G}, \alpha_{0}{ }^{S L}\right)$ ) that purchase the product under the negligence regime would have not purchased the product under strict liability. To explain this intuitively, note that with $x^{N G}=\chi^{F B}<\chi^{*}(\hat{a})=\chi^{S L}$ (see above), the maximized ex-ante net utility under the negligence rule exceeds the maximized ex-ante net utility under strict liability for the consumer who does not mispredict future product benefits and usage $\left(U_{1}{ }^{N G}(1)=\Omega^{F B}>U_{1}{ }^{S L}(1)\right)$. Since $a_{1}{ }^{N G}(\alpha)<a_{1}{ }^{S L}$ (see above), it follows by (2) that the effect of underestimation of future product benefits and usage (i.e. decrease in $\alpha$ when $\alpha<1$ ) on reducing the maximized ex-ante net utility is greater under strict liability than under negligence rule. Hence, there exist consumers, who underestimate the future benefits from the product, that would abstain from purchasing the product under strict liability but nevertheless choose to purchase the product under negligence rule.

In period 2, all consumers for whom $\alpha \geq 1$ ex post choose $a_{2}{ }^{N G}(\alpha)=a_{2}{ }^{N L}(\alpha)$ and realize expost net utility equal to ex-post net utility under no liability, $U_{2}{ }^{N L}(\alpha)$ (see (10)). The consumers with $\alpha<1$ who purchase the product (i.e. those with $\alpha \in\left[\alpha_{0}{ }^{N G}, 1\right)$ ) choose the ex-post activity level $a_{2}{ }^{N G}=\operatorname{argmax} a\left\{B(a)-C\left(x^{F B}\right)-a H\left(x^{F B}\right)\right\}=a^{*}\left(x^{F B}\right)=a^{F B}$ (see Figure 2). Consequently, maximized expost net utility for consumer of type $\alpha \in\left[\alpha_{0}^{N G}, 1\right)$ under the negligence rule equals $B\left(a^{F B}\right)-C\left(x^{F B}\right)-a^{F B} H\left(x^{F B}\right)>0$ and is independent of $\alpha$. Therefore, maximized ex-post net utility of consumer of type $\alpha$ under the negligence rule equals 


$$
U_{2}^{N G}(\alpha)= \begin{cases}0 & \text { if } \alpha<\alpha_{0}^{N G} \\ B\left(a^{F B}\right)-C\left(x^{F B}\right)-a^{F B} H\left(x^{F B}\right) & \text { if } \alpha \in\left[\alpha_{0}^{N G}, 1\right) \\ U_{2}^{N L}(\alpha) & \text { if } \alpha \geq 1 .\end{cases}
$$

In sum, under the negligence rule with due standard of precaution equal to $x^{N G}=\chi^{F B}$, consumers of type $\alpha \geq 1$ are offered the product characterized by safety level $x^{N G}(\alpha) \geq x^{F B}$ at price $p^{N G}(\alpha)=C\left(x^{N L}(\alpha)\right)$, where $x^{N L}(\alpha)$ is defined by (7) and (8). Consumers of type $\alpha<1$ are offered the product characterized by safety level $x^{F B}$ and charged a relatively high price $p^{N G}=C\left(x^{F B}\right)$ which is independent of consumer type $\alpha<1$. Thus, only the consumers of type $\alpha>\alpha_{0}{ }^{N G}$, where $\alpha_{0}{ }^{N G}<1$, actually purchase the product. Social welfare under the negligence rule equals

$$
\Omega^{N G}=\int_{\alpha_{0}^{N G}}^{\infty} U_{2}^{N G}(\alpha) f(\alpha) d \alpha=\Omega^{F B}\left[F(1)-F\left(\alpha_{0}^{N G}\right)\right]+\int_{1}^{\infty} U_{2}^{N L}(\alpha) f(\alpha) d \alpha
$$

\section{Comparing Legal Regimes: Welfare Analysis}

The preceding section characterized equilibria and social welfare under each of the three alternative legal regimes: no liability (NL), strict liability (SL), and negligence (NG). In this section, we explore how the three legal regimes compare from the social welfare standpoint. We follow the conventional approach (see, e.g., Shavell 1980, Miceli 1997, Cooter and Ulen 2011) and ignore any administrative and litigation costs associated with operating a given legal regime.

To set the stage, we first contrast the three regimes based on the attained ex-post net consumer utility for given type $\alpha$. Note that since firms earn zero profits, ex-post net utility of consumer of type $\alpha$ also equals social welfare from the production and consumption of the product offered to consumer of type $\alpha$.

Proposition 1: (Ex-Post Net Utility for Consumer of Type $\alpha$ under Different Legal Regimes)

(i) When $\alpha<\alpha_{0}{ }^{N G}, U_{2}{ }^{N L}(\alpha)>U_{2}{ }^{N G}(\alpha)=U_{2}{ }^{S L}(\alpha)=0$.

(ii) When $\alpha \in\left(\alpha_{0}{ }^{N G}, 1\right), U_{2}{ }^{N G}(\alpha)>\max \left\{U_{2}{ }^{S L}, U_{2}{ }^{N L}(\alpha)\right\}$.

(iii) When $\alpha \in\left(1, \alpha^{\prime}\right), U_{2}{ }^{N G}(\alpha)=U_{2}{ }^{N L}(\alpha)>U_{2}{ }^{S L}(\alpha)$. 
(iv) When $\alpha>\alpha^{\prime}, U_{2}{ }^{S L}(\alpha)>U_{2}{ }^{N G}(\alpha)=U_{2}{ }^{N L}(\alpha)$, where $\alpha^{\prime}$ is the value of $\alpha>1$ such that $U_{2}{ }^{S L}=U_{2}{ }^{N L}(\alpha)$.

The above result is summarized in Figure $3{ }^{11}$ The consumers who underestimate the future benefits from a risky product to the greatest extent $\left(\alpha<\alpha 0^{N G}\right)$ attain the highest ex-post net utility under the no liability regime. These consumers abstain from purchasing the product under both strict liability and negligence rule. The consumers who either moderately underestimate or moderately overestimate the future benefits from a product $\left(\alpha \in\left(\alpha_{0}{ }^{N G}, \alpha^{\prime}\right)\right)$ attain the highest expost net utility under the negligence rule. For consumers who moderately underestimate future product benefits and usage $\left(\alpha \in\left(\alpha_{0}^{N G}, 1\right)\right)$, negligence ensures the highest level of ex-post net utility among the three regimes. For consumers who moderately overestimate future product benefits and usage $\left(\alpha \in\left(1, \alpha^{\prime}\right)\right)$, negligence is de facto a no liability regime and results in higher ex-post net consumer utility than strict liability. Finally, consumers who notably overestimate future product benefits and usage $\left(\alpha>\alpha^{\prime}\right)$ attain the highest ex-post net utility under the strict liability rule.

The discussion in Section 3 implies that, once the full extent of consumer heterogeneity as captured by $\alpha$ is taken into account, social welfare under each of the three regimes in general falls short of first-best social welfare, $\Omega^{F B}$. Proposition 1 and inspection of expressions (11), (14), and (17) further reveals that the social welfare comparison of the three regimes is contingent on the underlying distribution of consumers based on the extent and direction of their mispredictions of future product benefits and usage. In particular, for an arbitrary distribution of $\alpha$, there in general exists no unconditionally best among the three legal regimes. However,

\footnotetext{
${ }^{11}$ Figure 3 assumes that there exists no $\alpha=\alpha^{\prime \prime}<1$ such that $U_{2}{ }^{N L}(\alpha)=U_{2}{ }^{S L}(\alpha)$. In that case, part (ii) of Proposition 1 says that $U_{2}{ }^{N G}(\alpha)>U_{2}{ }^{N L}(\alpha)>U_{2}{ }^{S L}(\alpha)$ when $\alpha \in\left(\alpha_{0}{ }^{N G}, 1\right)$. If $\alpha=\alpha^{\prime \prime}<1$ such that $U_{2}{ }^{N L}(\alpha)=U_{2}{ }^{S L}(\alpha)$ exists, however, $U_{2}{ }^{N G}(\alpha)>U_{2}{ }^{S L}(\alpha)>U_{2}{ }^{N L}(\alpha)$ for all $\alpha \in\left(\alpha_{0}{ }^{N G}, \alpha^{\prime \prime}\right)$, where $U_{2}{ }^{N L}\left(\alpha^{\prime \prime}\right)=U_{2}{ }^{S L}\left(\alpha^{\prime \prime}\right)$ and $\alpha^{\prime \prime}<1$, and $U_{2}{ }^{N G}(\alpha)>U_{2}{ }^{N L}(\alpha)>U_{2}{ }^{S L}(\alpha)$ for all $\alpha \in\left(\alpha^{\prime \prime}, 1\right)$. Regardless of whether $\alpha=\alpha^{\prime \prime}<1$ such that $U_{2}{ }^{N L}(\alpha)=U_{2}{ }^{S L}(\alpha)$ exists or not, however, negligence yields the highest ex-post net consumer utility for all $\alpha \in\left(\alpha_{0}{ }^{N G}, 1\right)$.
} 
drawing on Proposition 1, pairwise comparison of the relative social desirability of alternative legal regimes is nevertheless possible under specific assumptions about the shifts in the distribution of $\alpha$.

Corollary 1(a): (NL vs. NG)

Let $F_{1}(\alpha)$ and $F_{2}(\alpha)$ be two cumulative distribution functions and $f_{1}(\alpha)$ and $f_{2}(\alpha)$ the associated density functions that satisfy the following properties:

(i) $\quad f_{1}(\alpha) \leq f_{2}(\alpha)$ for all $\alpha \leq \alpha 0^{N G}$ and there exists a set $O_{1} \subseteq\left(0, \alpha_{0}^{N G}\right)$ with $\mu\left(O_{1}\right)>0$ such that $f_{1}(\alpha)<f_{2}(\alpha)$ for all $\alpha \in O_{1}$,

(ii) $f_{1}(\alpha) \geq f_{2}(\alpha)$ for all $\alpha \in\left[\alpha_{0}{ }^{N G}, \infty\right)$ and there exists a set $O_{2} \subseteq\left[\alpha_{0}{ }^{N G}, \infty\right)$ with $\mu\left(O_{2}\right)>0$ such that $f_{1}(\alpha)>f_{2}(\alpha)$ for all $\alpha \in O_{2}$,

where $\mu(\cdot)$ is a Lebesgue measure. Define $\Delta_{i}^{N L, N G} \equiv \Omega_{i}^{N L}-\Omega_{i}^{N G}$ for a given distribution $F_{i}(\alpha)$ with corresponding density function $f_{i}(\alpha), i \in\{1,2\}$. Then, $\Delta_{2}{ }^{N L, N G}>\Delta_{1}{ }^{N L, N G}$.

The relative social desirability of no liability versus negligence increases when the share of consumers who significantly underestimate future product benefits increases and, at the same time, the share of consumers who either moderately underestimate or overestimate future product benefits decreases (see Figure 4(a)). In this case, the social opportunity cost of foregone transactions under the negligence rule (purchases that would have taken place under no liability) increases while the social benefits from higher ex-post net utility for consumers who moderately underestimate the future benefits from the product (see Figure 3) decrease.

\section{Corollary 1(b): (NG vs. SL)}

Let $F_{3}(\alpha)$ and $F_{4}(\alpha)$ be cumulative distribution functions and $f_{3}(\alpha)$ and $f_{4}(\alpha)$ the associated density functions that satisfy the following properties:

(i) $f_{3}(\alpha) \leq f_{4}(\alpha)$ for all $\alpha \in\left[\alpha_{0}{ }^{N G}, \alpha^{\prime}\right)$ and there exists a set $O_{3} \subseteq\left[\alpha_{0}{ }^{N G}, \alpha^{\prime}\right)$ with $\mu\left(O_{3}\right)>0$ such that $f_{3}(\alpha)<f_{4}(\alpha)$ for all $\alpha \in O_{3}$,

(ii) $f_{3}(\alpha) \geq f_{4}(\alpha)$ for all $\alpha \notin\left[\alpha_{0}^{N G}, \alpha^{\prime}\right)$ and there exists a set $O_{4} \subseteq\left(0, \alpha_{0}{ }^{N G}\right) \cup\left(\alpha^{\prime}, \infty\right]$ with $\mu\left(O_{4}\right)>0$ such that $f_{3}(\alpha)>f_{4}(\alpha)$ for all $\alpha \in O_{4}$.

Define $\Delta_{i}^{N G, S L} \equiv \Omega_{i}^{N G}-\Omega_{i}^{S L}$ for a given distribution $F_{i}(\alpha)$ with corresponding density function $f_{i}(\alpha)$, $i \in\{3,4\}$. Then, $\Delta 4^{N G, S L}>\Delta_{3}^{N G, S L}$.

The relative social desirability of negligence rule versus strict liability increases when there is an increase in the share of consumers who either moderately underestimate or 
moderately overestimate future product benefits and, at the same time, a decrease in the share of consumers who significantly overestimate future product benefits and usage (see Figure 4(b)). Because consumers who significantly overestimate the future benefits from the product attain higher ex-post net utility under strict liability than under negligence (see Figure 3), under the above-described shift in the distribution of consumers there is a decrease in the aggregate net social benefits of strict liability rule over negligence. In addition, there is an increase in the net aggregate social benefits of negligence rule over strict liability because consumers who moderately mispredict future product benefits and purchase the product are ex post better off under negligence than they would be under strict liability.

Corollary 1(c): (SL vs. NL)

Let $F_{5}(\alpha)$ and $F_{6}(\alpha)$ be cumulative distribution functions and $f_{5}(\alpha)$ and $f_{6}(\alpha)$ the associated density functions that satisfy the following properties:

(i) $f_{5}(\alpha) \leq f_{6}(\alpha)$ for all $\alpha \geq \alpha^{\prime}$ and there exists a set $O_{5} \subseteq\left[\alpha^{\prime}, \infty\right)$ with $\mu\left(O_{5}\right)>0$ such that $f_{5}(\alpha)<f_{6}(\alpha)$ for all $\alpha \in \mathrm{O}_{5}$,

(ii) $\quad f_{5}(\alpha) \geq f_{6}(\alpha)$ for all $\alpha<\alpha^{\prime}$ and there exists a set $O_{6} \subseteq\left(0, \alpha^{\prime}\right)$ with $\mu\left(O_{6}\right)>0$ such that $f_{5}(\alpha)>f_{6}(\alpha)$ for all $\alpha \in \mathrm{O}_{6}$.

Define $\Delta_{i}^{S L, N L} \equiv \Omega_{i}{ }^{S L}-\Omega_{i}{ }^{N L}$ for a given distribution $F_{i}(\alpha)$ with corresponding density function $f_{i}(\alpha)$, $i \in\{5,6\}$, and suppose that $U_{2}{ }^{N L}(\alpha)=U_{2}{ }^{S L}(\alpha)$ for $\alpha=\alpha^{\prime}>1$ only. Then, $\Delta_{6}{ }^{S L, N L}>\Delta 5^{S L, N L}$.

The relative social desirability of strict liability versus no liability increases when the share of consumers who notably overestimate future product benefits and usage increases at the expense of all other consumer types (see Figure 4(c)). In this case, there is an increase in the aggregate net social benefits of strict liability rule over no liability that arise because consumers who significantly overestimate the future benefits from the product attain higher ex-post net utility under strict liability than under no liability (see Figure 3). Furthermore, the above-noted shift in the distribution of consumers decreases the aggregate social benefits of no liability over strict liability that arise because consumers who significantly underestimate future product 
benefits and usage abstain from purchasing the product under strict liability but not under no liability (see Figure 3).

Finally, the following result, which follows directly from Proposition 1 and Figure 3, identifies the legal regime that yields the highest social welfare among the three regimes for specific distributions of $\alpha$.

Corollary 2: (Social-Welfare-Maximizing Legal Regime)

(i) If $f(\alpha)>0$ for all $\alpha \in O_{7}$, where $O_{7} \subseteq\left(0, \alpha_{0}{ }^{N G}\right)$ such that $\mu\left(O_{7}\right)>0$, and $f(\alpha)=0$ for all $\alpha \notin O_{7}$, then social welfare is highest under no liability.

(ii) If $f(\alpha)>0$ for all $\alpha \in O_{8}$, where $O_{8} \subseteq\left(\alpha_{0}^{N G}, \alpha^{\prime}\right)$ such that $\mu\left(O_{8}\right)>0$, and $f(\alpha)=0$ for all $\alpha \notin O 8$, then social welfare is highest under negligence.

(iii) If $f(\alpha)>0$ for all $\alpha \in O_{9}$, where $O_{9} \subseteq\left(\alpha^{\prime}, \infty\right)$ such that $\mu\left(O_{9}\right)>0$, and $f(\alpha)=0$ for all $\alpha \notin O 9$, then social welfare is highest under strict liability.

What are some concrete policy implications of the above analysis? As suggested in Section 2.1, the exact form of distribution of consumers based on the extent and direction of their misprediction of future product benefits and usage plausibly varies across categories of durable consumer products. Most categories of durable consumer products, ranging from consumer electronics to domestic appliances and lawn and garden equipment, are arguably characterized by small to moderate extent of misprediction. Part (ii) of Corollary 2 shows that for such products negligence outperforms no liability and strict liability from the social welfare standpoint.

Durable consumer products that we would expect to elicit considerable overestimation of future product benefits among the potential consumers includes products that stimulate positive emotions by their very design and products that are subject to particularly aggressive advertising by the manufacturers. Examples include sports cars, durable wellness products such as temperature adjustable beds, and fitness equipment. Part (iii) of Corollary 2 implies that for such products strict liability yields higher social welfare than negligence and no liability. 
Finally, durable consumer products that evoke noteworthy underestimation of future product benefits are likely few. Indeed, when the allocation of losses caused by product use is governed by either strict liability or negligence rule, as is the case in U.S. and Europe (see, e.g., Geistfeld 2009, Shavell 2004: 222-223), our analysis predicts that products characterized by significant underestimation of future benefits and usage will not be traded in the marketplace in the first place. Taking this into account, examples of products such that the consumers tend to underestimate future benefits from their usage might include newly introduced, potentially highly innovative products for which the complete extent of prospective benefits might not yet be fully apparent at the time when the product is first offered on the market (e.g., the first personal computers when launched in the 1970s). In addition, underestimation of future product benefits may be common for a subset of retail medical devices (such as automatic insulin pumps, reusable hypodermic syringes, and medical mobility scooters), which the consumer has been advised to purchase in order to cope with a serious medical condition. In these cases, ex-ante underestimation of ex-post benefits from the product may be driven by the consumer's adverse emotional state caused by a negative medical diagnosis shortly preceding the decision to purchase the product. Part (i) of Corollary 2 suggests that for such products no liability gives rise to the highest social welfare among the three legal regimes.

\section{Conclusion}

We shed new light on the ongoing scholarly and policy debate about the choice of appropriate legal regimes for allocation of losses from defective consumer products by examining the performance of alternative liability rules when potential buyers of durable consumer products are, due to cognitive errors and biases, prone to mispredicting future product benefits and usage. Since the expected harm from a durable consumer product all else equal increases with the level 
of activity associated with the product's usage, the repercussions of consumers' misprediction of product benefits and usage for market outcomes critically depend on the liability regime in place.

Our analysis shows that no liability, strict liability, and negligence rule differ markedly with respect to how the consumers' misprediction of future product benefits and usage affects not only the equilibrium safety and actual product usage, but, importantly, also the extent of the market supported by the legal regime. No liability maximizes the extent of the market in that all consumers purchase the product variety offered to their type as captured by the direction and extent of their misprediction. However, as the price and the level of product safety under no liability reflect consumer's ex-ante choice of activity, the consumer's ex-post welfare under no liability decreases with the extent of his or her misprediction.

In contrast, under strict producer liability rational firms, upon recognizing the threat of moral hazard that leads to excessive ex-post product usage, offer a correspondingly safe product at a high price regardless of the extent and direction of consumer's misprediction. Consumers who ex ante notably underestimate true product benefits and usage thus abstain from purchasing the product. The consumers who purchase the product, however, realize ex-post welfare that is independent of the extent of their misprediction. Finally, the extent of the market supported by the negligence regime exceeds that under strict liability but falls short of that under no liability. The reason is that the firms serving consumers who ex ante underestimate product benefits and usage in equilibrium satisfy the due standard of care and offer a high level of product safety, which comes at the cost of a relatively high product price.

Consequently, which liability regime is optimal is ultimately contingent on the underlying distribution of consumers based on the direction and extent of their mispredictions. Social welfare is highest under no liability when consumers substantially underestimate product 
benefits and usage; under strict liability when consumers substantially overestimate product benefits and usage; and under negligence whenever the extent of consumers' misprediction is moderate or non-existent. To the extent that different categories of durable consumer products tend to elicit different direction and extent of mispredictions of future product benefits and usage, our analysis suggests that the choice of the appropriate liability regime may vary across product categories. 


\section{References}

Abel, Andrew B. 2002. "An Exploration of the Effects of Pessimism and Doubt on Asset Returns." Journal of Economic Dynamics and Control, 26:7-8, 1075-1092.

American Law Institute. 1997. Restatement of the Law (Third) of Torts: Products Liability. Philadelphia, PA: The American Law Institute.

Blumenthal, Jeremy A. 2005. "Law and the Emotions: The Problems of Affective Forecasting." Indiana Law Journal, 80:2, 155-238.

Brookins, Philip, Adriana Lucas, and Dmitry Ryvkin. 2014. "Reducing Within-Group Overconfidence Through Group Identity and Between-Group Confidence Judgments." Journal of Economic Psychology, 44, 1-12.

Brown, John P. 1973. "Toward an Economic Theory of Liability." Journal of Legal Studies, 2:2, 323-349.

Busse, Meghan R., Devin G. Pope, Jaren C. Pope, Jorge Silva-Risso. 2012. "Projection Bias in the Car and Housing Markets." NBER Working Paper No. 18212.

Calabresi, Guido and Alvin K. Klevorick. 1985. "Four Tests for Liability in Torts." Journal of Legal Studies, 14:3, 585-627.

Conlin, Michael, Ted O'Donoghue, and Timothy J. Vogelsang. 2007. "Projection Bias in Catalog Orders." American Economic Review, 97:4, 1217-1249.

Cooter, Robert and Thomas S. Ulen. 2011. Law \& Economics, Sixth Edition. Boston: AddisonWesley.

Daughety, Andrew F. and Jennifer F. Reinganum. 2013. "Economic Analysis of Products Liability: Theory." In: Arlen, Jennifer (ed.), Research Handbook on the Economics of Torts. Cheltenham, UK: Edward Elgar, 69-96.

DellaVigna, Stefano. 2009. "Psychology and Economics: Evidence from the Field." Journal of Economic Literature, 47:2, 315-372.

Fellner-Röhling, Gerlinde and Sebastian Krügel. 2014. "Judgmental Overconfidence and Trading Activity." Journal of Economic Behavior and Organization, 107:B, 827-842.

Garoupa, Nuno and Thomas S. Ulen. 2014. "The Economics of Activity Levels in Tort Liability and Regulation." In: Miceli, Thomas J. and Matthew J. Baker (eds.), Research Handbook on Economic Models of Law. Cheltenham, UK: Edward Elgar, 33-53.

Geistfeld, Mark A. 2009. "Products Liability." In: Faure, Michael (ed.), The Encyclopedia of Law and Economics, Second Edition. Cheltenham, UK: Edward Elgar, 287-340.

Goldberg, John C.P. and Benjamin C. Zipursky. 2010. "The Easy Case for Products Liability Law: A Response to Professors Polinsky and Shavell." Harvard Law Review, 123:8, 19191948.

Grubb, Michael D. 2009. "Selling to Overconfident Consumers." American Economic Review, 99:5, 1770-1807.

Heidhues, Paul, Botond Köszegi, and Philipp Strack. 2016. "Unrealistic Expectations and Misguided Learning." Unpublished manuscript.

Hsee, Christopher K. and Reid Hastie. 2006. "Decision and Experience: Why Don't We Choose What Makes Us Happy?" Trends in Cognitive Sciences, 10:1, 31-37. 
Hylton, Keith N. 2013. "The Law and Economics of Products Liability." Notre Dame Law Review, 88:5, 2457-2514.

Jolls, Christine, Cass R. Sunstein, and Richard Thaler. 1998. "A Behavioral Approach to Law and Economics." Stanford Law Review, 50, 1471-1550.

Kliger, Doron and Ori Levy. 2008. "Projection Bias by Investors: A Market Approach." Journal of Economic Behavior and Organization, 66:3-4, 657-668.

Korobkin, Russell B. and Thomas S. Ulen. 2000. "Law and Behavioral Science: Removing the Rationality Assumption from Law and Economics." California Law Review, 88:4, 10511144.

Kőszegi, Botond. 2014. "Behavioral Contract Theory." Journal of Economic Literature, 52:4, 1075-1118.

Landes, William M. and Richard A. Posner. 1985. "A Positive Economic Analysis of Products Liability." Journal of Legal Studies, 14:3, 535-567.

Loewenstein, George. 2000. "Emotions in Economic Theory and Economic Behavior." American Economic Review Papers and Proceedings, 90:2, 426-432.

Loewenstein, George, Ted O'Donoghue and Matthew Rabin. 2003. "Projection Bias in Predicting Future Utility." Quarterly Journal of Economics, 118:4, 1209-1248.

Loewenstein, George and David Schkade. 1999. "Wouldn't It Be Nice? Predicting Future Feelings." In: Kahneman, Daniel, Edward Diener, and Norbert Schwarz (eds.), Well-Being: The Foundations of Hedonic Psychology. New York: Russell Sage Foundation, 85-105.

Miceli, Thomas J. 1997. Economics of the Law: Torts, Contracts, Property, Litigation. Oxford, UK: Oxford University Press.

Moore, Don A. and Paul J. Healy. 2008. "The Trouble With Overconfidence." Psychological Review, 115:2, 502-517.

Nussim, Jacob and Avraham D. Tabbach. 2009. "A Revised Model of Unilateral Accidents." International Review of Law and Economics, 29:2, 169-177.

Oliver, Richard L. 1977. "Effect of Expectation and Disconfirmation on Postexposure Product Evaluations: An Alternative Interpretation." Journal of Applied Psychology, 62:4, 480-486.

Oliver, Richard L. 1980. "A Cognitive Model of the Antecedents and Consequences of Satisfaction Decisions." Journal of Marketing Research, 17:4, 460-469.

Polinsky, A. Mitchell and Steven Shavell. 2010. "The Uneasy Case for Product Liability." Harvard Law Review, 123:6, 1437-1492.

Polinsky, A. Mitchell and William P. Rogerson. 1983. "Products Liability, Consumer Misperceptions, and Market Power." Bell Journal of Economics, 14:2, 581-589.

Quoidbach, Jordi and Elizabeth W. Dunn. 2010. "Personality Neglect: The Unforeseen Impact of Personal Dispositions on Emotional Life." Psychological Science, 21:12, 1783-1786.

Rabin, Matthew. 1998. "Psychology and Economics." Journal of Economic Literature, 36:1, 1146.

Rick, Scott and George Loewenstein. 2009. "The Role of Emotion in Economic Behavior." In: Lewis, Michael, Jeannette M. Haviland-Jones, and Lisa Feldman Barrett (eds.), Handbook of Emotions, Third Edition. New York, NY: The Guilford Press, 138-156. 
Salanie, Bernard. 2005. The Economics of Contracts, A Primer, Second Edition. Cambridge, MA: The MIT Press.

Sandroni, Alvaro and Francesco Squintani. 2007. "Overconfidence, Insurance, and Paternalism." American Economic Review, 97:5, 1994-2004.

Shavell, Steven. 1980. "Strict Liability versus Negligence." Journal of Legal Studies, 9:1, 1-25.

Shavell, Steven. 2004. Foundations of Economic Analysis of Law. Belknap Press/Harvard University Press.

Shavell, Steven. 2007. "Liability for Accidents." In: Polinsky, A. Mitchell and Steven Shavell (eds.), Handbook of Law and Economics, Volume 1. Amsterdam, Netherlands: Elsevier, 139182.

Simons, Kenneth W. 2008. "Tort Negligence, Cost-Benefit Analysis, and Tradeoffs: A Closer Look at the Controversy." Loyola of Los Angeles Law Review, 41:4, 1171-1224.

Simonsohn, Uri. 2009. "Weather To Go To College." Economic Journal, 120:543, 270-280.

Spreng, Richard A., Scott B. MacKenzie, and Richard W. Olshavsky. 1996. "A Reexamination of the Determinants of Consumer Satisfaction." Journal of Marketing, 60:3, 15-32.

Sunstein, Cass R. Behavioral Law and Economics. Cambridge, UK: Cambridge University Press.

Thaler, Richard H. and Cass R. Sunstein. 2008. Nudge: Improving Decisions about Health, Wealth, and Happiness. New Haven, CT: Yale University Press.

Ulen, Thomas S. 2014. "Behavioral Law and Economics: Law, Policy, and Science." Supreme Court Economic Review, 21:1, 5-42.

Viscusi, W. Kip. Reforming Products Liability. Cambridge, MA: Harvard University Press.

Wilson, Timothy D. and Daniel T. Gilbert. 2003. "Affective Forecasting." Advances in Experimental Social Psychology, 35, 345-411. 


\section{Appendix A}

\section{To show that $a^{*}(x)$ is steeper than $x^{*}(a)$ in Figure 2:}

Let expression (4) define $x^{1}(a)$ and expression (5) define $x^{2}(a)$, so that $a^{*}(x)$ defined in the text is the inverse of $x^{1}(a)$ and $x^{*}(a) \equiv x^{2}(a)$. Then, differentiating both sides of (4) with respect to $a$ and rearranging terms gives

$$
\frac{d x^{1}}{d a}=\frac{B^{\prime \prime}}{H^{\prime}}>0
$$

Similarly, differentiating both sides of (5) with respect to $a$ and rearranging terms yields

$$
\frac{d x^{2}}{d a}=\frac{-H^{\prime}}{a H^{\prime \prime}+C^{\prime \prime}}>0
$$

The signs of (A1) and (A2) follow from the properties of the functions $B(\cdot), C(\cdot)$, and $H(\cdot)$. Hence, in a diagram with $a$ on the horizontal axis and $x$ on the vertical axis, as in Figure 2, both $a^{*}(x)$ and $x^{*}(a)$ are upward-sloping. We have $\Omega_{a a}=B^{\prime \prime}<0, \Omega_{x x}=-C^{\prime \prime}-a H^{\prime \prime}<0$, and $\Omega_{a x}=-H^{\prime}>0$. The

assumption that second-order sufficient conditions for (3) to attain maximum at $\left(a^{F B}{ }_{,} x^{F B}\right)$ are satisfied further implies that

$$
\Omega_{a a} \Omega_{x x}-\Omega_{a x}^{2}=B^{\prime \prime}\left[-C^{\prime \prime}-a H^{\prime \prime}\right]-\left[H^{\prime}\right]^{2}>0 .
$$

Comparing (A1) and (A2) while drawing on (A3) then implies that $d x^{1} / d a>d x^{2} / d a$ at $\left(a^{F B}, x^{F B}\right)$. That is, in a diagram with $a$ on the horizontal axis and $x$ on the vertical axis, as in Figure 2, at point $\left(a^{F B}, x^{F B}\right)$ the function $a^{*}(x)$ defined by (4) is steeper than the function $x^{*}(a)$ defined by (5).

\section{Proof that $a_{1}{ }^{N L}(\alpha)$ and $x^{N L}(\alpha)$ are increasing in $\alpha$ :}

Take the system (7) and (8), which defines $a_{1}{ }^{N L}(\alpha)$ and $x^{N L}(\alpha)$. Differentiating (7) and (8), respectively, with respect to $\alpha$ and collecting terms yields:

$$
\left[\begin{array}{cc}
B_{a a} & -H^{\prime} \\
-H^{\prime} & -a_{1}^{N L}(\alpha) H^{\prime \prime}-C^{\prime \prime}
\end{array}\right]\left[\begin{array}{l}
a_{1}^{N L^{\prime}}(\alpha) \\
x^{N L^{\prime}}(\alpha)
\end{array}\right]=\left[\begin{array}{c}
-B_{a \alpha} \\
0
\end{array}\right] .
$$

The determinant of the two-by-two matrix on the left-hand side of (A4) is positive by the secondorder sufficient condition for a maximum of $U_{1}{ }^{N L}(a, x, \alpha)=B(a, \alpha)-C(x)-a H(x)$ with respect to variables $a$ and $x$. Therefore, it follows that

$$
\operatorname{sign}\left\{\frac{d a_{1}^{N L}}{d \alpha}\right\}=\operatorname{sign}\left\{B_{a \alpha}\left[a H^{\prime \prime}+C^{\prime \prime}\right]\right\}
$$




$$
\operatorname{sign}\left\{\frac{d x^{N L}}{d \alpha}\right\}=\operatorname{sign}\left\{-B_{a \alpha} H^{\prime}\right\} .
$$

The expressions in the curly brackets on the right-hand side of (A5) and (A6) are positive by (2) and properties of the functions $H(\cdot)$ and $C(\cdot)$. Thus, $a_{1}{ }^{N L}(\alpha)$ and $x^{N L}(\alpha)$ are monotonically increasing in $\alpha$.

\section{Proof of Lemma 1:}

Note that $U_{1}{ }^{N L}(\alpha)$ defined in (9) can be expressed as

$$
U_{1}{ }^{N L}(\alpha)=\max _{a, x}\{B(a, \alpha)-C(x)-a H(x)\}
$$

Differentiating (A7) with respect to $\alpha$ and using the Envelope Theorem gives

$$
\frac{d U_{1}^{N L}(\alpha)}{d \alpha}=\left.\frac{\partial B(a, \alpha)}{\partial \alpha}\right|_{a=a_{1}^{N L}(\alpha)}>0,
$$

where the sign of the right-hand side of (A8) follows from (1). Hence, $U_{1}{ }^{N L}(\alpha)$ is increasing for all $\alpha$.

To show that $U_{1}{ }^{N L}(\alpha) \rightarrow 0$ as $\alpha \rightarrow 0$, we proceed as follows. First, note that

$$
U_{1}{ }^{N L}(\alpha)=\max _{a, x} \Omega(a, x, \alpha)=\Omega\left(a_{1}{ }^{N L}(\alpha), x^{N L}(\alpha), \alpha\right),
$$

where $\Omega(a, x, \alpha)=B(a, \alpha)-C(x)-a H(x)$ is a continuous function defined for $a \geq 0, x \geq 0$, and $\alpha>0$. Observe that $\Omega(a, x, 1) \equiv \Omega(a, x)$ defined in (3). Since for all $\alpha>0$ we have $\Omega(0,0, \alpha)=0$ it follows that $U_{1}{ }^{N L}(\alpha)=\max _{a, x} \Omega(a, x, \alpha) \geq 0$ for all $\alpha>0$. Second, we have $\Omega(a, x, \alpha) \leq B(a, \alpha) \leq \max _{a} B(a, \alpha)$ for all $x, a$ and given $\alpha$. Hence, $\max _{a, x} \Omega(a, x, \alpha) \leq \max a B(a, \alpha)$. Combining these facts, it follows that

$$
0 \leq U_{1}{ }^{N L}(\alpha)=\max _{a, x} \Omega(a, x, \alpha) \leq \max _{a} B(a, \alpha) .
$$

for all $\alpha>0$. Since we assume that $\max _{a} B(a, \alpha)=B(\hat{a}(\alpha), \alpha) \rightarrow 0$ as $\alpha \rightarrow 0$ (see Section 2.1), we have that $U_{1}{ }^{N L}(\alpha) \rightarrow 0$ as $\alpha \rightarrow 0$.

\section{Proof of Lemma 2:}

First, observe that

$$
U_{2}{ }^{N L}(1)=B\left(a^{*}\left(x^{N L}(1)\right)-C\left(x^{N L}(1)\right)-a^{*}\left(x^{N L}(1)\right) H\left(x^{N L}(1)\right)=B\left(a^{F B}\right)-C\left(x^{F B}\right)-a^{F B} H\left(x^{F B}\right) \equiv \Omega^{F B},(\mathrm{~A}\right.
$$

which is positive by (6).

Second, note that (10) can be expressed as

$$
U_{2}{ }^{N L}(\alpha)=\max _{a}\left\{B(a)-C\left(x^{N L}(\alpha)\right)-a H\left(x^{N L}(\alpha)\right)\right\} .
$$


Recall that $a_{2}{ }^{N L}(\alpha)=a^{*}\left(x^{N L}(\alpha)\right)=\operatorname{argmax} a\left\{B(a)-C\left(x^{N L}(\alpha)\right)-a H\left(x^{N L}(\alpha)\right)\right\}$. Hence, differentiating (A12) with respect to $\alpha$ and using the Envelope Theorem gives

$$
\frac{d U_{2}^{N L}(\alpha)}{d \alpha}=-C^{\prime}\left(x^{N L}(\alpha)\right) \cdot x^{N L^{\prime}}(\alpha)-a^{*}\left(x^{N L}(\alpha)\right) \cdot H^{\prime}\left(x^{N L}(\alpha)\right) \cdot x^{N L^{\prime}}(\alpha),
$$

which can in turn be expressed as

$$
\frac{d U_{2}^{N L}(\alpha)}{d \alpha}=x^{N L^{\prime}}(\alpha)\left[-C^{\prime}\left(x^{N L}(\alpha)\right)-a^{*}\left(x^{N L}(\alpha)\right) \cdot H^{\prime}\left(x^{N L}(\alpha)\right)\right] .
$$

To sign the right-hand side of (A13), we must sign the expression

$$
-C^{\prime}\left(x^{N L}(\alpha)\right)-a^{*}\left(x^{N L}(\alpha)\right) H^{\prime}\left(x^{N L}(\alpha)\right) .
$$

To this end, define the function $\Psi(x, a)=-C^{\prime}(x)-a H^{\prime}(x)$. We can then write (A14) as

$$
\frac{d U_{2}^{N L}(\alpha)}{d \alpha}=x^{N L^{\prime}}(\alpha) \cdot \Psi\left(x^{N L}(\alpha), a^{*}\left(x^{N L}(\alpha)\right) .\right.
$$

Since $x^{N L^{\prime}}(\alpha)>0$ by (A6), the sign of the right-hand side of (A16) is determined by the sign of $\Psi\left(x^{N L}(\alpha), a^{*}\left(x^{N L}(\alpha)\right)\right)$.

The following then characterizes the properties of the function $\Psi(x, a)$. We have $\partial \Psi(x, a) / \partial x=-C^{\prime \prime}-a H^{\prime \prime}<0$ and $\partial \Psi(x, a) / \partial a=-H^{\prime}>0$. These properties are illustrated in Figure A1. $\Psi(x, a)>0$ for all points below the function $x^{*}(a)$ and $\Psi(x, a)<0$ for all points above the function $x^{*}(a)$. Furthermore, by (5) we have $\Psi\left(x^{*}(a), a\right)=0$.

For $\alpha>1$ we have $x^{N L}(\alpha)>x^{F B}$, and the corresponding equilibrium ex-post level of activity equals $a^{*}\left(x^{N L}(\alpha)\right)>a^{F B}$. This scenario corresponds to a point such as point B in Figure A1. At point B, we have $\Psi(\cdot, \cdot)<0$, and hence the right-hand side of (A16) is negative. It follows that for $\alpha>1, U_{2}^{N L}(\alpha)$ is decreasing in $\alpha$.

For $\alpha<1$ we have $x^{N L}(\alpha)<x^{F B}$, and the corresponding equilibrium ex-post level of activity equals $a^{*}\left(x^{N L}(\alpha)\right)<a^{F B}$. This scenario corresponds to a point such as point $\mathrm{C}$ in Figure A1. At point C, we have $\Psi(\cdot)>$,0 , and hence the right-hand side of (A16) is positive. It follows that for $\alpha<1, U_{2}^{N L}(\alpha)$ is increasing in $\alpha$.

To show that $U_{2}{ }^{N L}(\alpha)<0$ as $\alpha \rightarrow \infty$, we first show that $x^{N L}(\alpha) \rightarrow \infty$ as $\alpha \rightarrow \infty$. To this end, recall the assumptions that for every $a, B(a, \alpha) \rightarrow \infty$ and $\partial B(a, \alpha) / \partial a \rightarrow \infty$ as $\alpha \rightarrow \infty$ (see Section 2.1). Note also that $\hat{a}(\alpha) \rightarrow \infty$ as $\alpha \rightarrow \infty$. Since $x^{N L}(\alpha)$ is monotonically increasing in $\alpha$ by (A6), the limit of $x^{N L}(\alpha)$ as $\alpha \rightarrow \infty$ is either finite and equal to $x_{l}$ or infinite. Suppose that 
$\lim _{\alpha \rightarrow \infty} x^{N L}(\alpha)=x_{l}$ and therefore finite. $x^{N L}(\alpha)$ and $a_{1}{ }^{N L}(\alpha)$ are defined by (7) and (8). Then, from (8), $\lim _{\alpha \rightarrow \infty} a_{1}^{N L}(\alpha)=-\frac{C^{\prime}\left(x_{l}\right)}{H^{\prime}\left(x_{l}\right)} \equiv a_{l}$, which is finite. Similarly, from (7), $\lim _{\alpha \rightarrow \infty} \frac{\partial B(a(\alpha), \alpha)}{\partial a}=H^{\prime}\left(x_{l}\right)$, which is also finite. We show that the finite nature of $\lim _{\alpha \rightarrow \infty} \frac{\partial B(a(\alpha), \alpha)}{\partial a}$ is in contradiction with other assumptions and, therefore, that $\lim _{\alpha \rightarrow \infty} x^{N L}(\alpha)$ cannot be finite. Since $\lim _{\alpha \rightarrow \infty} a_{1}^{N L}(\alpha)=a_{l}$ and $\lim _{\alpha \rightarrow \infty} \hat{a}(\alpha)=\infty$, for a given $\delta>0$ there exists an $\underline{\alpha}$ such that for any $\alpha>\underline{\alpha}, 0<\underline{\alpha}-\delta<a(\alpha)<\underline{\alpha}+\delta<\hat{a}(\alpha)$. Because $\partial B(a, \alpha) / \partial a$ is decreasing on the interval $(0, \hat{a}(\alpha)]$, it follows that $\frac{\partial \mathrm{B}(\alpha+\delta, \alpha)}{\partial a}<\frac{\partial \mathrm{B}(a(\alpha), \alpha)}{\partial a}<\frac{\partial \mathrm{B}(\alpha-\delta, \alpha)}{\partial a}$. Because $\partial B(a, \alpha) / \partial a \rightarrow \infty$ as $\alpha \rightarrow \infty$ by assumption, we have $\lim _{\alpha \rightarrow \infty} \frac{\partial B(\underline{\alpha}+\delta, \alpha)}{\partial a}=\lim _{\alpha \rightarrow \infty} \frac{\partial B(\underline{\alpha}-\delta, \alpha)}{\partial a}=\infty$ and, therefore, $\lim _{\alpha \rightarrow \infty} \frac{\partial B(a(\alpha), \alpha)}{\partial a}=\infty$. But this contradicts the above conclusion, based on the premise that the limit of $x^{N L}(\alpha)$ as $\alpha \rightarrow \infty$ is finite, that $\lim _{\alpha \rightarrow \infty} \frac{\partial B(a(\alpha), \alpha)}{\partial a}$ is finite. Thus, $x^{N L}(\alpha) \rightarrow \infty$ as $\alpha \rightarrow \infty$.

Second, because $H(x) \rightarrow 0$ as $x \rightarrow \infty$, we have $H\left(x^{N L}(\alpha)\right) \rightarrow 0$ as $\alpha \rightarrow \infty$. Third, by (4), $a^{*}(x) \rightarrow \hat{a}$ as $H(x) \rightarrow 0$ and so $a^{*}\left(x^{N L}(\alpha)\right) \rightarrow \hat{a}$ as $\alpha \rightarrow \infty$. Finally, as the function $C(\cdot)$ is monotonically increasing with $C(x) \rightarrow \infty$ as $x \rightarrow \infty, C\left(x^{N L}(\alpha)\right) \rightarrow \infty$ as $\alpha \rightarrow \infty$. Hence, we have that, as $\quad \alpha \rightarrow \infty, \quad B\left(a^{*}\left(x^{N L}(\alpha)\right)-C\left(x^{N L}(\alpha)\right)-a^{*}\left(x^{N L}(\alpha)\right) H\left(x^{N L}(\alpha)\right) \rightarrow B(\hat{a})-\infty-\hat{a} \cdot 0=B(\hat{a})-\infty, \quad\right.$ which $\quad$ is negative.

Finally, to clarify the relationship between $U_{2}{ }^{N L}(\alpha)$ and $U_{1}{ }^{N L}(\alpha)$, note that (9) can be expressed as

$$
U_{1}^{N L}(\alpha)=\max a\left\{B(a, \alpha)-C\left(x^{N L}(\alpha)\right)-a H\left(x^{N L}(\alpha)\right)\right\}
$$

and (10) can be expressed as

$$
U_{2}{ }^{N L}(\alpha)=\max a\left\{B(a, 1)-C\left(x^{N L}(\alpha)\right)-a H\left(x^{N L}(\alpha)\right)\right\}
$$

since $B(a, 1) \equiv B(a)$. it follows that $U_{2}{ }^{N L}(1)=U_{1}{ }^{N L}(1)$. By $(1)$, we have $B(a, \alpha)>B(a, 1)$ for $\alpha>1$ and $B(a, \alpha)<B(a, 1)$ for $\alpha<1$. Hence, $U_{1}{ }^{N L}(\alpha)<U_{2}{ }^{N L}(\alpha)$ if $\alpha<1$ and $U_{1}{ }^{N L}(\alpha)>U_{2}{ }^{N L}(\alpha)$ if $\alpha>1$.

\section{Proof of Lemma 3:}

By the Envelope Theorem and (1), $B(\hat{a}(\alpha), \alpha)$ is increasing in $\alpha$. Hence, $U_{1}{ }^{S L}(\alpha)$ defined in (12) is increasing in $\alpha$. With $U_{1}{ }^{S L}(1)>0$, by continuity $U_{1}{ }^{S L}(\alpha)>0$ for $\alpha>1$ as well as for values of $\alpha$ smaller than, but still sufficiently close to, 1 . Since $B(\hat{a}(\alpha), \alpha) \rightarrow 0$ as $\alpha \rightarrow 0$, however, 
$U_{1}{ }^{S L}(\alpha) \rightarrow-C\left(x^{*}(\hat{a})\right)-\hat{a} H\left(x^{*}(\hat{a})\right)<0$ as $\alpha \rightarrow 0$. Thus, there exists $\alpha_{0}{ }^{S L} \in(0,1)$ such that $U_{1}{ }^{S L}(\alpha)<0$ for $\alpha<\alpha_{0} S L, U_{1}{ }^{S L}\left(\alpha_{0}{ }^{S L}\right)=0$, and $U_{1}{ }^{S L}(\alpha)>0$ for $\alpha>\alpha 0^{S L}$.

\section{Proof that $x^{N G}(\alpha)$ never exceeds $x^{F B}$ when $\alpha<1$ :}

In the text, we show that firms will never choose $x^{N G}(\alpha)<x^{F B}$ when $\alpha<1$. Here, we show that firms will also never offer $x^{N G}(\alpha)>X^{F B}$. Note that when firms satisfy the due standard of precaution, they operate under a de facto no liability regime. Thus, consumers choose ex-ante level of activity and competitive pressure induces firms to offer a level of safety that maximizes $U_{1}^{N L}(a, x, \alpha)=B(a, \alpha)-C(x)-a H(x)$ subject to the constraint $x \geq x^{F B}$. The resulting Kuhn-Tucker conditions for this constrained maximization problem are:

$$
\begin{gathered}
\frac{\partial B(a, \alpha)}{\partial a}-H(x)=0 \\
-a H^{\prime}(x)-C^{\prime}(x)+\lambda=0 \\
-x^{F B}+x \leq 0, \lambda \geq 0, \lambda\left[-x^{F B}+x\right]=0
\end{gathered}
$$

where $\lambda$ is the Lagrange multiplier. Suppose that $x>x^{F B}$. From the complementary slackness condition in (A21) it follows that $\lambda=0$. (A19) and (A20) then reduce to (7) and (8), respectively. It follows that $x=x^{N L}(\alpha)<x^{F B}$ (see Figure 2), a contradiction. Thus, we must have $x=x^{F B}$.

\section{Proof that $p^{N L}(\alpha)<p^{N G}<p^{S L}$ for all $\alpha<1$ :}

Recall that $p^{S L}=C\left(x^{S L}\right)+a^{S L} H\left(x^{S L}\right)=C\left(x^{*}(\hat{a})\right)+\hat{a} H\left(x^{*}(\hat{a})\right)$ and $x^{*}(\hat{a})>x^{F B}$ (see Section 3.2). Because the function $C(\cdot)$ is increasing, it follows that $C\left(x^{*}(\hat{a})\right)>C\left(x^{F B}\right)$, where $C\left(x^{F B}\right)=p^{N G}$ (see Section 3.3). Hence, $p^{S L}>p^{N G}$. Also, because $x^{N L}(\alpha)<x^{F B}$ for $\alpha<1$ and $p^{N L}(\alpha)=C\left(x^{N L}(\alpha)\right)$ (see Section 3.1), we have $p^{N G}>p^{N L}(\alpha)$. Therefore, $p^{N L}(\alpha)<p^{N G}<p^{S L}$ for all $\alpha<1$.

\section{Proof that $a_{1}{ }^{N G}(\alpha)$ is increasing and $a_{1}{ }^{N L}(\alpha)<a_{1}{ }^{N G}(\alpha)<a_{1}{ }^{S L}(\alpha)$ for all $\alpha<1$ :}

To show that $a_{1}{ }^{N G}(\alpha)$ is increasing, note that $a_{1}{ }^{N G}(\alpha)$ is defined by

$$
\frac{\partial B(a, \alpha)}{\partial a}=H\left(x^{F B}\right)
$$

Letting $a=a_{1}{ }^{N G}(\alpha)$ in (A22), differentiating both sides of (A22) with respect to $\alpha$, and rearranging terms, 


$$
\frac{d a_{1}^{N G}}{d \alpha}=-\frac{B_{a \alpha}}{B_{a a}} .
$$

The right-hand side of (A23) is positive by the properties of the function $B(\cdot, \cdot)$.

To show that $a_{1}{ }^{N L}(\alpha)<a_{1}{ }^{N G}(\alpha)<a_{1}{ }^{S L}(\alpha)$, note that $a_{1}{ }^{N L}(\alpha)$ is defined by

$$
\frac{\partial B(a, \alpha)}{\partial a}=H\left(x^{N L}(\alpha)\right)
$$

and $a_{1} S L(\alpha)=\hat{a}(\alpha)$ is defined by

$$
\frac{\partial B(a, \alpha)}{\partial a}=0
$$

Since $0<\chi^{N L}(\alpha)<\chi^{F B}$ for $\alpha<1$ and the function $H(\cdot)$ is decreasing, we have $H\left(x^{N L}(\alpha)\right)>H\left(x^{F B}\right)$. Then, because $\partial B(a, \alpha) / \partial a$ is decreasing in $a(B(a, \alpha)$ is strictly concave in a for any given $\alpha$; see Section 2.1), comparison of (A22), (A24), and (A25) implies that $a_{1}{ }^{N L}(\alpha)<a_{1}{ }^{N G}(\alpha)<a_{1}{ }^{S L}(\alpha)$.

\section{Proof of Lemma 4:}

To show that $U_{1}{ }^{N G}(\alpha)$ is increasing for all $\alpha>0$, note that for $\alpha<1, U_{1}{ }^{N G}(\alpha)$ defined in (15) can be expressed as

$$
U_{1}^{N G}(\alpha)=\max a\left\{B(a, \alpha)-C\left(x^{F B}\right)-a H\left(x^{F B}\right)\right\} .
$$

Differentiating (A26) with respect to $\alpha$ and using the Envelope Theorem,

$$
\frac{d U_{1}^{N G}(\alpha)}{d \alpha}=\left.\frac{\partial B(a, \alpha)}{\partial \alpha}\right|_{a=a_{1}^{N G}(\alpha)}>0
$$

where the sign of the right-hand side of (A27) follows from (1). For $\alpha \geq 1, U_{1}{ }^{N G}(\alpha)=U_{1}{ }^{N L}(\alpha)$, and hence, by (A7), $U_{1}{ }^{N G}(\alpha)$ is also increasing for all $\alpha \geq 1$.

To show that $U_{1}{ }^{N G}(\alpha)<U_{1}{ }^{N L}(\alpha)$ for $\alpha<1$, note that since $x^{F B} \neq X^{N L}(\alpha)$ for $\alpha \neq 1$, we have

$$
U_{1}{ }^{N L}(\alpha)=\max _{a, x}\{B(a, \alpha)-C(x)-a H(x)\}>\max _{a}\left\{B(a, \alpha)-C\left(x^{F B}\right)-a H\left(x^{F B}\right)\right\}=U_{1}{ }^{N G}(\alpha) .
$$

To show that $U_{1}{ }^{N G}(\alpha)>U_{1}{ }^{S L}(\alpha)$ for $\alpha<1$, note that from (12),

$$
\frac{d U_{1}^{S L}(\alpha)}{d \alpha}=\left.\frac{\partial B(a, \alpha)}{\partial \alpha}\right|_{a=a_{1}^{S L}(\alpha)=\hat{a}(\alpha)}>0
$$

Recall, next, that $a_{1}{ }^{N G}(\alpha)<a_{1}{ }^{S L}(\alpha)$ for all $\alpha<1$ (see above). By (2), the comparison of the righthand side of (A29) and (A27) then implies that $d U_{1}{ }^{S L}(\alpha) / d \alpha>d U_{1}{ }^{N G}(\alpha) / d \alpha$ for all $\alpha<1$. That is, the function $U_{1}{ }^{S L}(\alpha)$ is steeper than the function $U_{1}{ }^{N G}(\alpha)$. Since $U_{1}{ }^{S L}(1)<\Omega^{F B}$, but $U_{1}{ }^{N G}(1)=\Omega^{F B}$ 
(see Section 3.3), it follows that $U_{1}{ }^{N G}(\alpha)>U_{1}{ }^{S L}(\alpha)$ for all $\alpha<1$; that is, the function $U_{1}{ }^{N G}(\alpha)$ lies above the function $U_{1}{ }^{S L}(\alpha)$ for all $\alpha<1$.

Finally, since $U_{1}{ }^{N L}(\alpha)>U_{1}{ }^{N G}(\alpha)>U_{1}{ }^{S L}(\alpha)$ for all $\alpha<1, U_{1}{ }^{N L}(\alpha) \rightarrow 0$ as $\alpha \rightarrow 0$ by Lemma 1, and there exists $\alpha 0^{S L} \in(0,1)$ such that $U_{1}{ }^{S L}(\alpha)<0$ for all $\alpha<\alpha_{0}{ }^{S L}, U_{1}{ }^{S L}\left(\alpha_{0}{ }^{S L}\right)=0$, and $U_{1}{ }^{S L}(\alpha)>0$ for all $\alpha>\alpha_{0}{ }^{S L}$ by Lemma 3, it follows that there exists $\alpha_{0}{ }^{N G} \in\left(0, \alpha_{0}{ }^{S L}\right)$ such that $U_{1}{ }^{N G}(\alpha)<0$ for $\alpha<\alpha_{0}{ }^{N G}, U_{1}^{N G}\left(\alpha_{0}{ }^{N G}\right)=0$, and $U_{1}^{N G}(\alpha)>0$ for $\alpha>\alpha 0^{N G}$.

\section{Proof of Proposition 1:}

Follows directly from Figure 3, which is in turn based on expression (10) and Lemma 2, and expressions (13) and (16) with corresponding discussion.

\section{Proof of Corollaries 1(a)-1(c):}

To prove Corollary 1(a), note that for distribution $F_{i}(\alpha)$ with corresponding density function $f_{i}(\alpha)$ we have

$$
\Delta_{i}^{N L, N G} \equiv \Omega_{i}^{N L}-\Omega_{i}^{N G}=\int_{0}^{\infty} U_{2}^{N L}(\alpha) f_{i}(\alpha) d \alpha-\int_{0}^{\infty} U_{2}^{N G}(\alpha) f_{i}(\alpha) d \alpha
$$

Define $\phi^{N L, S L}(\alpha) \equiv U_{2}{ }^{N L}(\alpha)-U_{2}{ }^{N G}(\alpha)$ so that (A30) can be expressed as

$$
\Delta_{i}^{N L, N G}=\int_{0}^{\infty}\left[U_{2}^{N L}(\alpha)-U_{2}^{N G}(\alpha)\right] f_{i}(\alpha) d \alpha=\int_{0}^{\infty} \phi^{N L, N G}(\alpha) f_{i}(\alpha) d \alpha .
$$

Then,

$$
\Delta_{2}^{N L, N G}-\Delta_{1}{ }^{N L, N G}=\int_{0}^{\infty} \phi^{N L, N G}(\alpha)\left[f_{2}(\alpha)-f_{1}(\alpha)\right] d \alpha .
$$

The right-hand side of (A32) can in turn be expressed as

$$
\int_{0}^{\alpha_{0}^{N G}} \phi^{N L, N G}(\alpha)\left[f_{2}(\alpha)-f_{1}(\alpha)\right] d \alpha+\int_{\alpha_{0}^{N G}}^{\infty} \phi^{N L, N G}(\alpha)\left[f_{2}(\alpha)-f_{1}(\alpha)\right] d \alpha .
$$

The first term in (A33) can be expressed as

$$
\int_{\alpha \in O_{1}} \phi^{N L, N G}(\alpha)\left[f_{2}(\alpha)-f_{1}(\alpha)\right] d \alpha+\int_{\alpha \in\left(0, \alpha_{0}^{N G}\right) / O_{1}} \phi^{N L, N G}(\alpha)\left[f_{2}(\alpha)-f_{1}(\alpha)\right] d \alpha
$$

The first term in (A34) is positive since $\phi^{N L, N G}(\alpha)>0$ by Proposition 1 and $f_{2}(\alpha)>f_{1}(\alpha)$ for $\alpha \in O_{1}$ by supposition (i). The second term in (A34) is zero since $f_{2}(\alpha)=f_{1}(\alpha)$ for $\alpha \in\left(0, \alpha_{0}{ }^{N G}\right) / O_{1}$. Similarly, the second term in (A33) can be expressed as 


$$
\int_{\alpha \in O_{2}} \phi^{N L, N G}(\alpha)\left[f_{2}(\alpha)-f_{1}(\alpha)\right] d \alpha+\int_{\alpha \in\left(\alpha_{0}^{N G}, \infty\right) / O_{2}} \phi^{N L, N G}(\alpha)\left[f_{2}(\alpha)-f_{1}(\alpha)\right] d \alpha .
$$

The first term in (A35) is non-negative since $\phi^{N L, N G}(\alpha) \leq 0$ by Proposition 1 and $f_{2}(\alpha)<f_{1}(\alpha)$ for $\alpha \in \mathrm{O}_{2}$ by supposition (ii). The second term in (A35) is zero since $f_{2}(\alpha)=f_{1}(\alpha)$ for all $\alpha \in\left(\alpha_{0}{ }^{N G}, \infty\right) \backslash O_{2}$. Combining the above findings implies that the right-hand side of (A32) is positive and, hence, $\Delta_{2}{ }^{N L, N G}>\Delta_{1}{ }^{N L, N G}$. Proof of Corollaries 2(b) and 2(c) relies on analogous steps and is, hence, omitted.

\section{Proof of Corollary 2:}

Follows straightforwardly from expressions (11), (14), (17) and Proposition 1. 


\section{Appendix B}

In this appendix, we first characterize the negligence regime when the due standard of precaution deviates from $x^{F B}$, so that $x^{N G}=x^{F B}+\varepsilon$, perhaps due to court error $(\varepsilon)$. We let $x^{N G} \leq x^{*}(\hat{a})$, where $x^{*}(\hat{a})>X^{F B}$ is the optimal level of precaution for the ex-post level of activity associated with the use of a perfectly safe product or, equivalently, the equilibrium level of precaution under strict liability (see Section 3.2).

We first examine firms' incentives to satisfy or violate a given due standard of precaution $x^{N G} \leq x^{*}(\hat{a})$. Define $\alpha^{N G}\left(x^{N G}\right)$ as the value of $\alpha$ such that $x^{N L}(\alpha)=x(\alpha)=x^{N G}$. Note that since $x^{N L}(\alpha)$ is increasing in $\alpha$ (see Appendix A), $\alpha^{N G}\left(x^{N G}\right)$ is increasing in $x^{N G}$. Furthermore, since $x^{N L}(1)=x^{F B}$, it follows that $\alpha^{N G}\left(x^{N G}\right)<1$ if $x^{N G}<x^{F B}, \quad \alpha^{N G}\left(x^{F B}\right)=1$, and $\alpha^{N G}\left(x^{N G}\right)>1$ if $x^{N G} \in\left(x^{F B}, x^{*}(\hat{a})\right)$. The firms serving consumers of type $\alpha \geq \alpha^{N G}\left(x^{N G}\right)$ therefore always optimally choose to satisfy the due standard of precaution $x^{N G}$ and operate under a de facto no liability regime. It then follows that whenever $\alpha \geq \alpha^{N G}\left(x^{N G}\right)$, the consumers under the negligence rule choose the ex-ante level of activity equal to the ex-ante level of activity chosen under the no liability rule: $a_{1}{ }^{N G}(\alpha)=a_{1}{ }^{N L}(\alpha) \geq a^{F B}$.

Consider, next, a firm that serves consumers for whom $\alpha<\alpha^{N G}\left(x^{N G}\right)$. Suppose that such a firm violates the negligence standard and chooses $x^{\prime}<x^{N G}$. Then, the firm is subject to strict liability rule, in which case (see Section 3.2) the firm would optimally choose $x^{S L}=x^{*}(\hat{a}) \geq x^{N G}$. This contradicts the original supposition that the firm violates the negligence standard. Furthermore, the firm that offers a product with safety level $x<x^{N G}$ charges the price equal to $C(x)+a \hat{H}(x)$. Then, by analogous reasoning as in Section 3.3, competitors will offer a product with a higher safety level and at a lower prices. Hence, $x<x^{N G}$ is not an equilibrium. Under the negligence rule with $x^{N G}$, the firms serving consumers with $\alpha<\alpha^{N G}\left(x^{N G}\right)$ therefore satisfy the negligence standard by choosing $x^{N G}(\alpha)=x^{N G}$ and setting price equal to $C\left(x^{N G}\right)$ for all $\alpha<\alpha^{N G}\left(x^{N G}\right)$. Accordingly, when $\alpha<\alpha^{N G}\left(x^{N G}\right)$, the consumer's ex-ante activity level equals $a_{1}{ }^{N G}(\alpha)=\operatorname{argmax} a\left\{B(a, \alpha)-C\left(x^{N G}\right)-a H\left(x^{N G}\right)\right\}$, which is increasing in $\alpha$. The consumer's ex-ante net utility for a given $x^{N G}$ equals

$$
U_{1}^{N G}\left(\alpha, x^{N G}\right)= \begin{cases}B\left(a_{1}^{N G}(\alpha), \alpha\right)-C\left(x^{N G}\right)-a_{1}^{N G}(\alpha) H\left(x^{N G}\right) & \text { if } \alpha<\alpha^{N G}\left(x^{N G}\right) \\ U_{1}^{N L}(\alpha) & \text { if } \alpha \geq \alpha^{N G}\left(x^{N G}\right)\end{cases}
$$


where $U_{1}{ }^{N L}(\alpha)$ is defined in (9). The following result (proof is analogous to the proof of Lemma 4 and thus omitted) summarizes the properties of the function $U_{1}{ }^{N G}\left(\alpha, x^{N G}\right)$.

Lemma B1: $U_{1}^{N G}\left(\alpha, x^{N G}\right)$ is increasing in $\alpha$ for all $\alpha>0 . U_{1}^{N G}\left(\alpha, x^{N G}\right)<U_{1}{ }^{N L}(\alpha)$ for $\alpha<\alpha^{N G}\left(x^{N G}\right)$. Furthermore, there exists $\alpha_{0}^{N G}\left(x^{N G}\right)>0$ such that $U_{1}^{N G}\left(\alpha, x^{N G}\right)<0$ for all $\alpha<\alpha_{0}^{N G}\left(x^{N G}\right)$, $U_{1}^{N G}\left(\alpha_{0}{ }^{N G}\left(x^{N G}\right), x^{N G}\right)=0$, and $U_{1}{ }^{N G}\left(\alpha, x^{N G}\right)>0$ for all $\alpha>\alpha_{0}{ }^{N G}\left(x^{N G}\right)$, where $\alpha_{0}{ }^{N G}\left(x^{N G}\right)$ is increasing in $x^{N G}, \alpha_{0}^{N G}\left(x^{N G}\right)<\alpha^{N G}\left(x^{N G}\right)$, and $\alpha_{0}{ }^{N G}\left(x^{N G}\right)<\alpha_{0}{ }^{S L}$ for $x^{N G} \leq x^{F B}$.

That is, under negligence rule, consumers with the lowest values of $\alpha$ abstain from purchasing the product; all other consumers purchase the product. Note that if the due standard is particularly restrictive so that $x^{N G}>X^{F B}$, then $\alpha^{N G}\left(x^{N G}\right)>1$ (see above), and therefore even some consumers who ex ante overestimate the benefits of the product may choose not to purchase the product. Furthermore, the comparison of the threshold value of $\alpha$ such that the consumers under the negligence rule with standard $x^{N G}$ purchase the product with the corresponding threshold value under the strict liability rule is in general ambiguous and depends on $x^{N G}$. When $x^{N G} \leq x^{F B}$, consumers who under strict liability would have not purchased the product purchase the product under the negligence regime $\left(\alpha_{0}{ }^{N G}\left(x^{N G}\right)<\alpha_{0} S L\right)$. When $x^{N G} \in\left(x^{F B}, x^{*}(\hat{a})\right]$, however, the relationship between $\alpha_{0}{ }^{N G}\left(x^{N G}\right)$ and $\alpha_{0}{ }^{S L}$ is ambiguous.

In period 2, all consumers for whom $\alpha \geq \alpha^{N G}\left(x^{N G}\right)$ ex post choose $a_{2}{ }^{N G}(\alpha)=a_{2}{ }^{N L}(\alpha)$ and realize ex-post net utility equal to ex-post net utility under no liability, $U_{2}{ }^{N L}(\alpha)$. The consumers with values of $\alpha$ smaller than $\alpha^{N G}\left(x^{N G}\right)$ who nevertheless purchase the product at given due standard of precaution $x^{N G}$ (i.e. those with $\left.\alpha \in\left[\alpha_{0}^{N G}\left(x^{N G}\right), \alpha^{N G}\left(x^{N G}\right)\right)\right)$ choose the ex-post activity level $a_{2}{ }^{N G}=\operatorname{argmax} a\left\{B(a)-C\left(x^{N G}\right)-a H\left(x^{N G}\right)\right\}$. Thus, $a_{2}{ }^{N G}=a^{*}\left(x^{N G}\right)$. Consequently, ex-post net utility for consumer of type $\alpha \in\left[\alpha_{0}{ }^{N G}\left(x^{N G}\right), \alpha^{N G}\left(x^{N G}\right)\right)$ under the negligence rule with due standard of precaution $x^{N G} \leq X^{*}(\hat{a})$ equals

$$
U_{2}^{N G}\left(x^{N G}\right)=B\left(a^{*}\left(x^{N G}\right)\right)-C\left(x^{N G}\right)-a^{*}\left(x^{N G}\right) H\left(x^{N G}\right) .
$$

The following result (proof omitted) characterizes the properties of (B2):

Lemma B2: The ex-post net utility in (B2), which is independent of $\alpha$, is increasing for $x^{N G}<x^{F B}$, decreasing for $x^{N G}>\chi^{F B}$, and attains maximum at $x^{N G}=\chi^{F B}$.

Since $x^{N G}=x\left(\alpha^{N G}\right)$ by definition of $\alpha^{N G}\left(x^{N G}\right)$ (see above), (B2) can be expressed as

$$
U_{2}^{N G}\left(x^{N G}\right)=B\left(a^{*}\left(x\left(\alpha^{N G}\right)\right)-C\left(x\left(\alpha^{N G}\right)\right)-a^{*}\left(x\left(\alpha^{N G}\right)\right) H\left(x\left(\alpha^{N G}\right)\right)=U_{2}{ }^{N L}\left(\alpha^{N G}\left(x^{N G}\right)\right) .\right.
$$


Therefore, the ex-post net utility of consumer of type $\alpha$ who purchases the product, and hence the social welfare from the product offered to consumer of type $\alpha$, under the negligence standard $x^{N G} \leq x^{*}(\hat{a})$ equals

$$
U_{2}^{N G}\left(\alpha, x^{N G}\right)= \begin{cases}0 & \text { if } \alpha<\alpha_{0}^{N G}\left(x^{N G}\right) \\ U_{2}^{N L}\left(\alpha^{N G}\left(x^{N G}\right)\right) & \text { if } \alpha \in\left[\alpha_{0}^{N G}\left(x^{N G}\right), \alpha^{N G}\left(x^{N G}\right)\right) \\ U_{2}^{N L}(\alpha) & \text { if } \alpha \geq \alpha^{N G}\left(x^{N G}\right) .\end{cases}
$$
where $U_{2}{ }^{N L}(\alpha)$ is defined in (10). A family of functions $U_{2}{ }^{N G}\left(\alpha, x^{N G}\right)$, one for each value of $x^{N G}$, is shown in Figure B1. That is, for a given $x^{N G}$, each of these functions begins at the constant value equal to $U_{2}{ }^{N L}\left(\alpha^{N G}\left(x^{N G}\right)\right)$ for values of $\alpha$ greater or equal to $\alpha_{0}{ }^{N G}\left(x^{N G}\right)$ and smaller than $\alpha^{N G}\left(x^{N G}\right)$ and then coincides with $U_{2}{ }^{N L}(\alpha)$ for values of $\alpha$ greater than $\alpha^{N G}\left(x^{N G}\right)$. Social welfare under the negligence rule for a given standard $x^{N G}$ and distribution $F(\alpha)$ then equals

$$
\Omega^{N G}\left(x^{N G}\right)=U_{2}^{N L}\left(\alpha^{N G}\left(x^{N G}\right)\right)\left[F\left(\alpha^{N G}\left(x^{N G}\right)\right)-F\left(\alpha_{0}^{N G}\left(x^{N G}\right)\right)\right]+\int_{\alpha^{N G}\left(x^{N G}\right)}^{\infty} U_{2}^{N L}(\alpha) f(\alpha) d \alpha
$$

Upon comparing Figure B1 with Figure 3 it follows that none of the qualitative conclusions summarized in Section 4 change as long as the due standard of precaution does not significantly deviate from $x^{F B}$.

We next examine the characteristics of a socially optimal precaution standard when the exact distribution of $\alpha$ is known to the authorities (i.e. the courts) choosing the standard. That is, we ask: For a given known distribution of $\alpha$, what level of $x^{N G}$ maximizes social welfare (B5)? Differentiating (B5) with respect to $x^{N G}$ using Leibniz's rule and simplifying gives

$$
\frac{d \Omega^{N G}\left(x^{N G}\right)}{d x^{N G}}=-\frac{d \alpha_{0}^{N G}\left(x^{N G}\right)}{d x^{N G}} U_{2}^{N L}\left(\alpha^{N G}\left(x^{N G}\right)\right) f\left(\alpha_{0}^{N G}\left(x^{N G}\right)\right)+\frac{d U_{2}^{N G}\left(x^{N G}\right)}{d x^{N G}}\left[F\left(\alpha^{N G}\left(x^{N G}\right)\right)-F\left(\alpha_{0}^{N G}\left(x^{N G}\right)\right)\right] .
$$

The first term on the right-hand side of (B6) is the reduction in social welfare that arises because fewer consumers choose to purchase the product under a stricter precaution standard. The second term is the change in social welfare due to the fact that a stricter precaution standard also impacts the ex-post net utility of consumers who purchase the good (see Figure B1). By Lemma B2, the sign of this latter effect depends on the level of precaution standard $x^{N G}$. In particular, for $x^{N G} \geq x^{F B}$, the effect of a marginally stricter precaution standard on the ex-post net utility of consumers who purchase the good is non-positive. This, in turn, renders expression (B6) strictly negative for $x^{N G} \geq x^{F B}$ and implies that the socially optimal negligence standard $x^{N G}$ when the distribution of $\alpha$ is known should be set lower than $x^{F B}$. The function $\Omega^{N G}\left(x^{N G}\right)$ is continuous on 
the interval $\left[0, x^{F B}\right]$. By Weierstrass' Theorem, $\Omega^{N G}\left(x^{N G}\right)$ thus attains a maximum on the interval $\left[0, x^{F B}\right]$. Where exactly the maximum occurs, however, is unclear since it is without additional assumptions not possible to ascertain whether $\Omega^{N G}\left(x^{N G}\right)$ is monotonic or non-monotonic on the interval $\left[0, x^{F B}\right]$. 
Figures

Figure 1: The functions $B(a, \alpha)$ and $B(a, 1) \equiv B(a)$

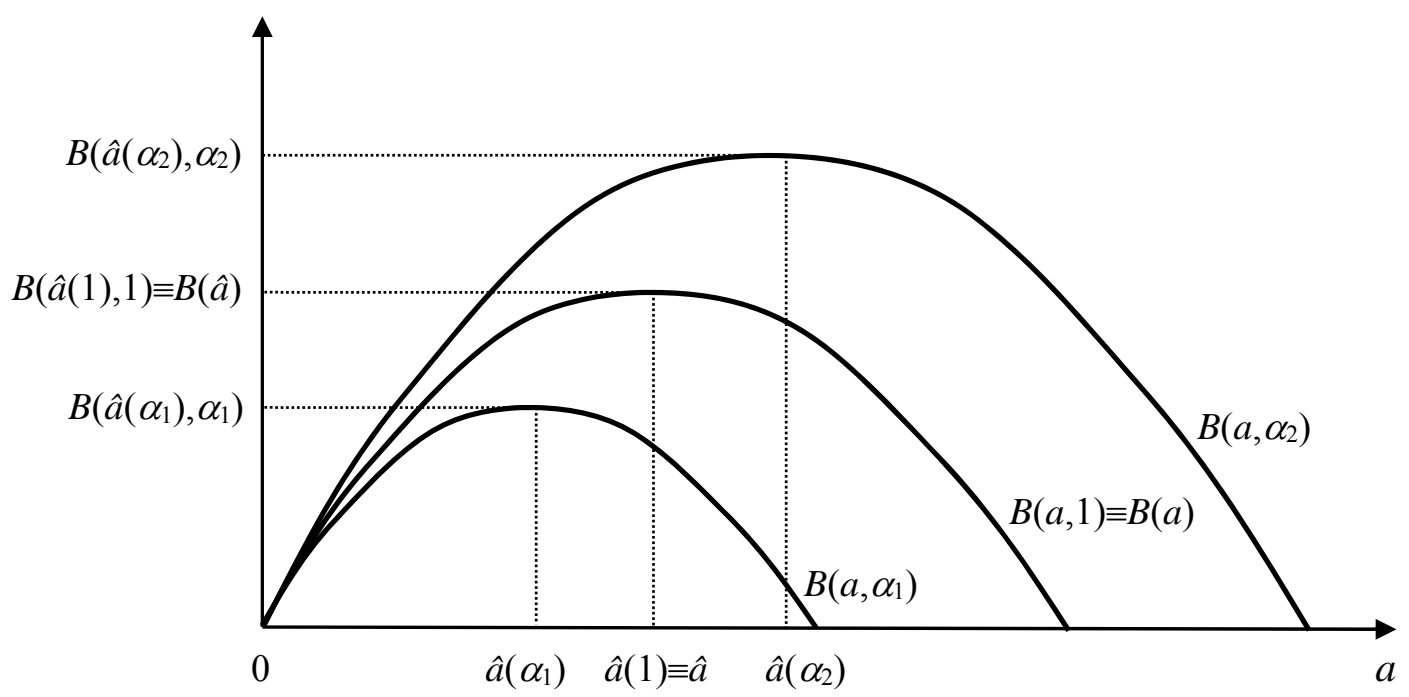

Notes: The figure assumes $\alpha_{2}>1>\alpha_{1}$. 
Figure 2: Equilibrium precaution and ex-ante and ex-post activity levels under different legal regimes

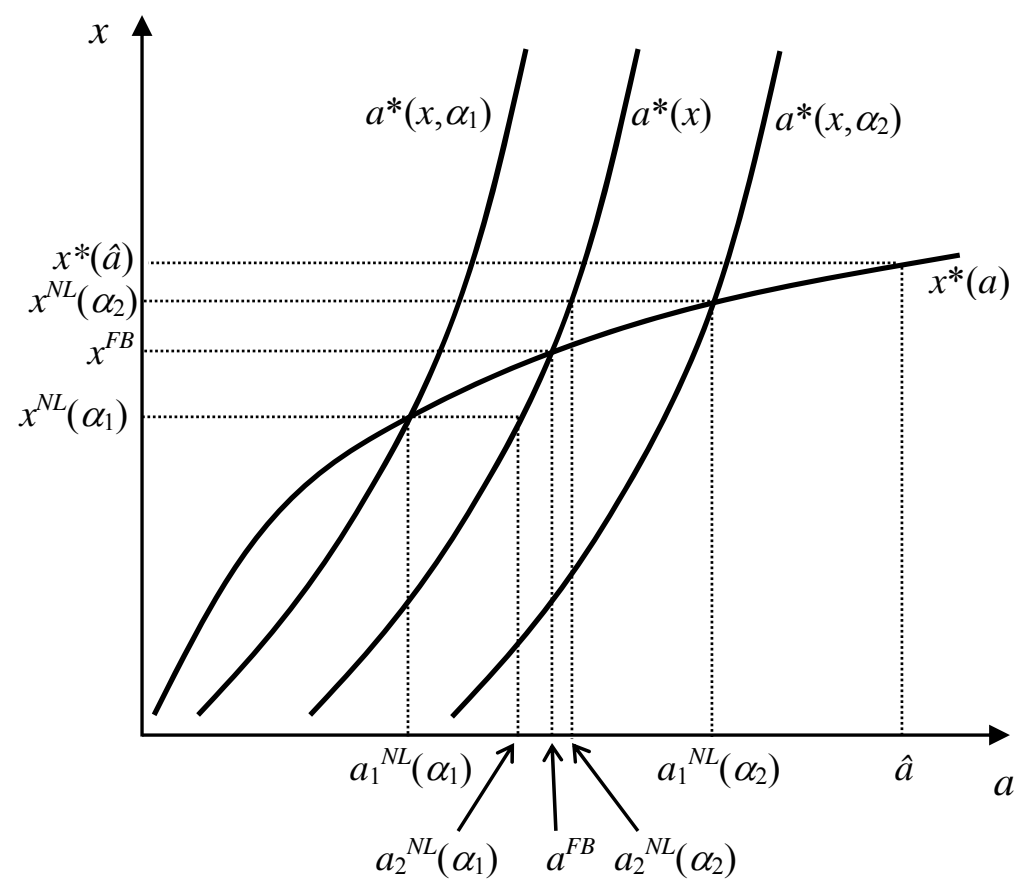

Notes: $a_{2}{ }^{N L}(\alpha)=a^{*}\left(x^{N L}(\alpha)\right), x^{F B}=x^{N L}(1), a^{F B}=a_{1}{ }^{N L}(1)=a_{2}{ }^{N L}(1), a^{*}(x) \equiv a^{*}(x, 1), a_{2}{ }^{N G}=a^{*}\left(x^{F B}\right)=a^{F B}$, and $x^{S L}=x^{*}(\hat{a})$. The figure assumes $\alpha_{2}>1>\alpha_{1}$. 
Figure 3: Ex ante and ex post net consumer utility under different legal regimes

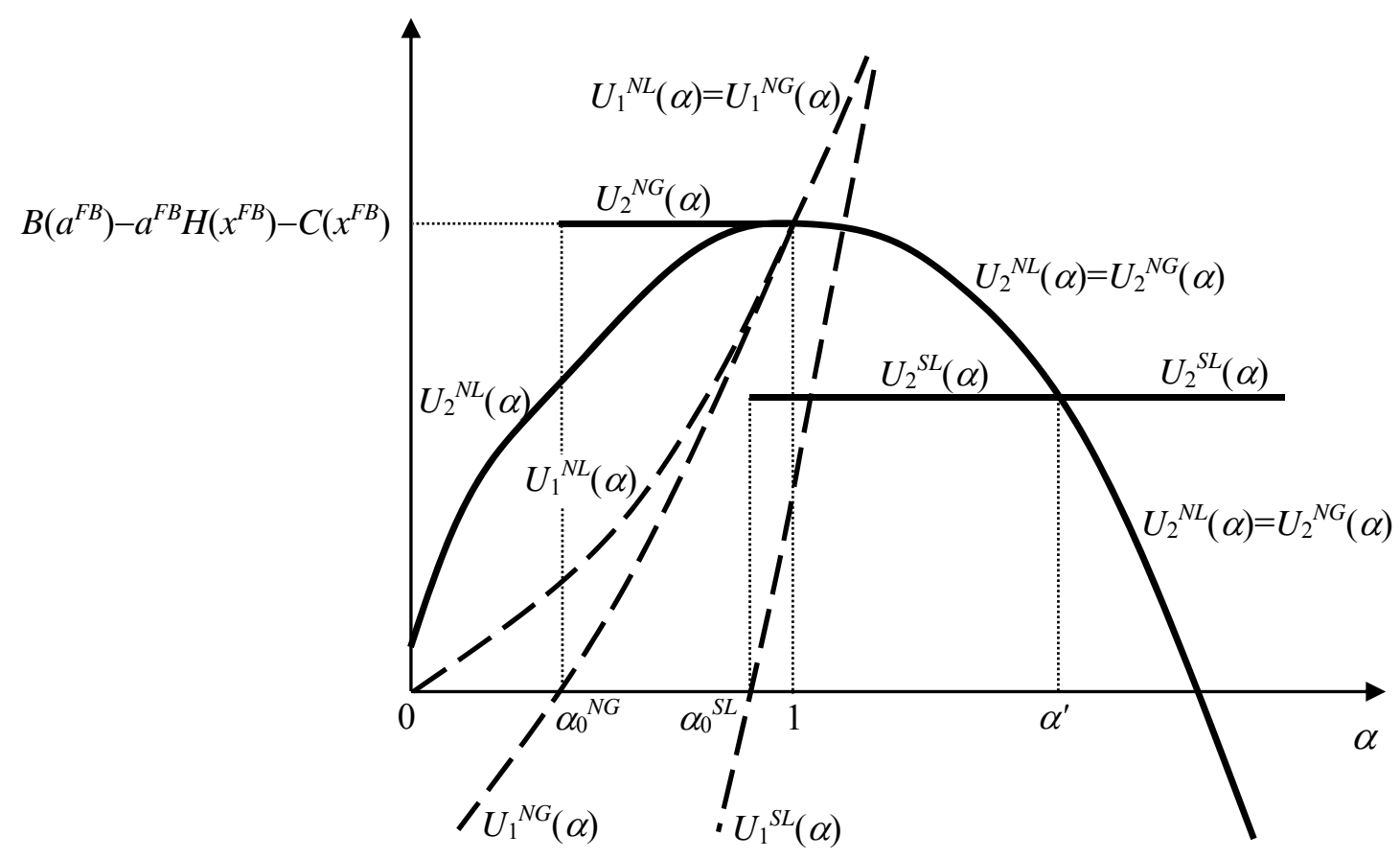

Notes: The figure assumes that there exists no $\alpha<1$ such that $U_{2}{ }^{N L}(\alpha)=U_{2}{ }^{S L}(\alpha)$. Note that $U_{2}{ }^{N G}(\alpha)=0$ for $\alpha<\alpha_{0}{ }^{N G}$ and $U_{2}{ }^{S L}(\alpha)=0$ for $\alpha<\alpha_{0}{ }^{S L}$; see expressions (16) and (13). 
Figure 4: Illustration of Corollaries 1(a)-1(c)

Figure 4(a)

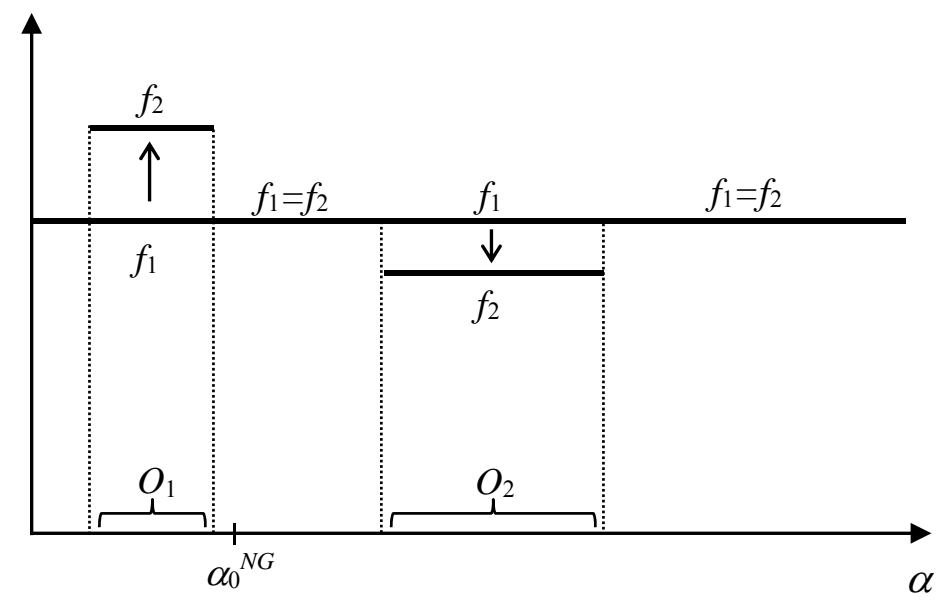

Figure 4(b)

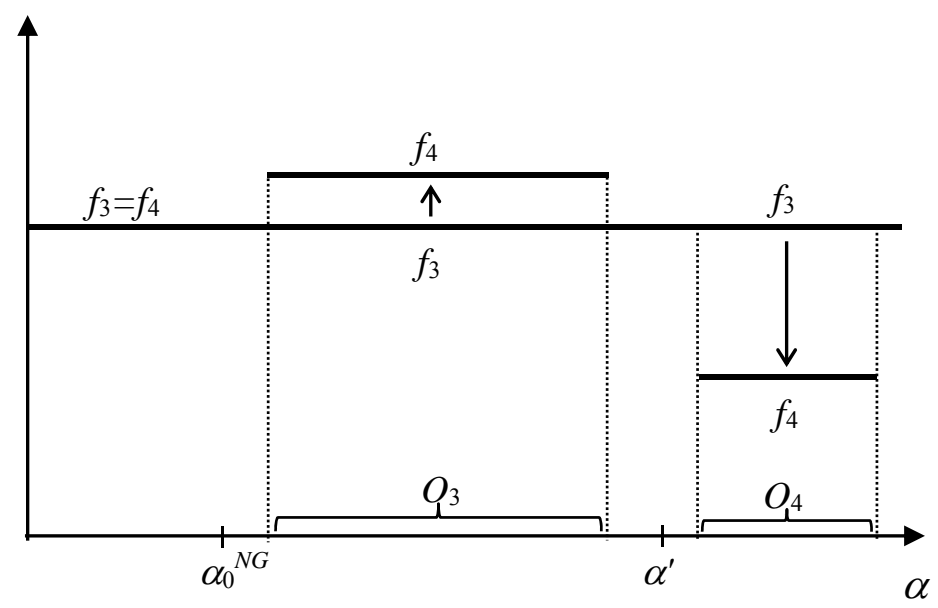

Figure 4(c)

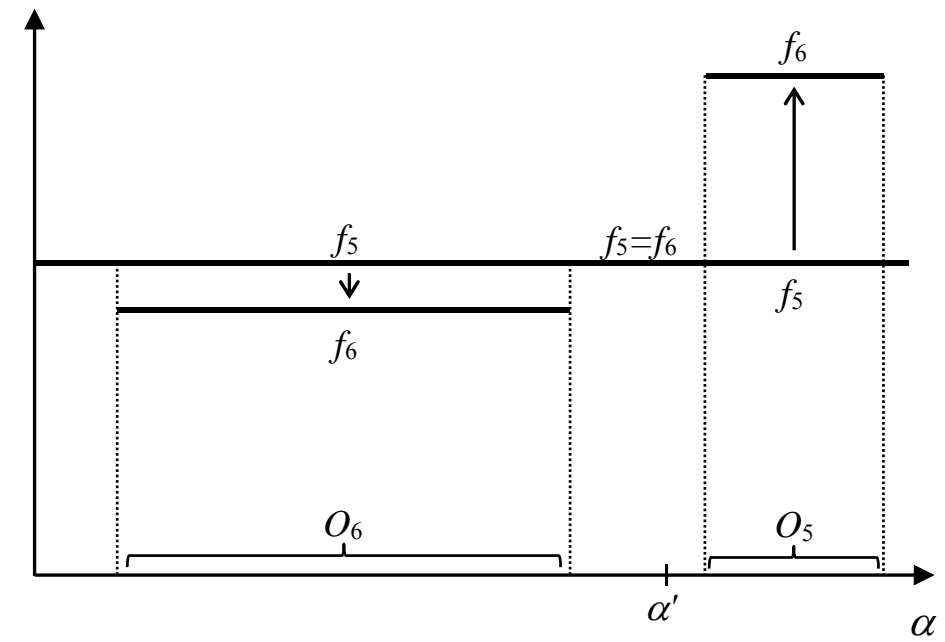

Notes: While Figures $4(\mathrm{a})-4(\mathrm{c})$ assume that $f_{1}, f_{3}$, and $f_{5}$ are uniform density functions, none of the Corollaries $1(a)-1(c)$ rests on the uniformity assumption. 
Figure A1: Illustration of proof of Lemma 2

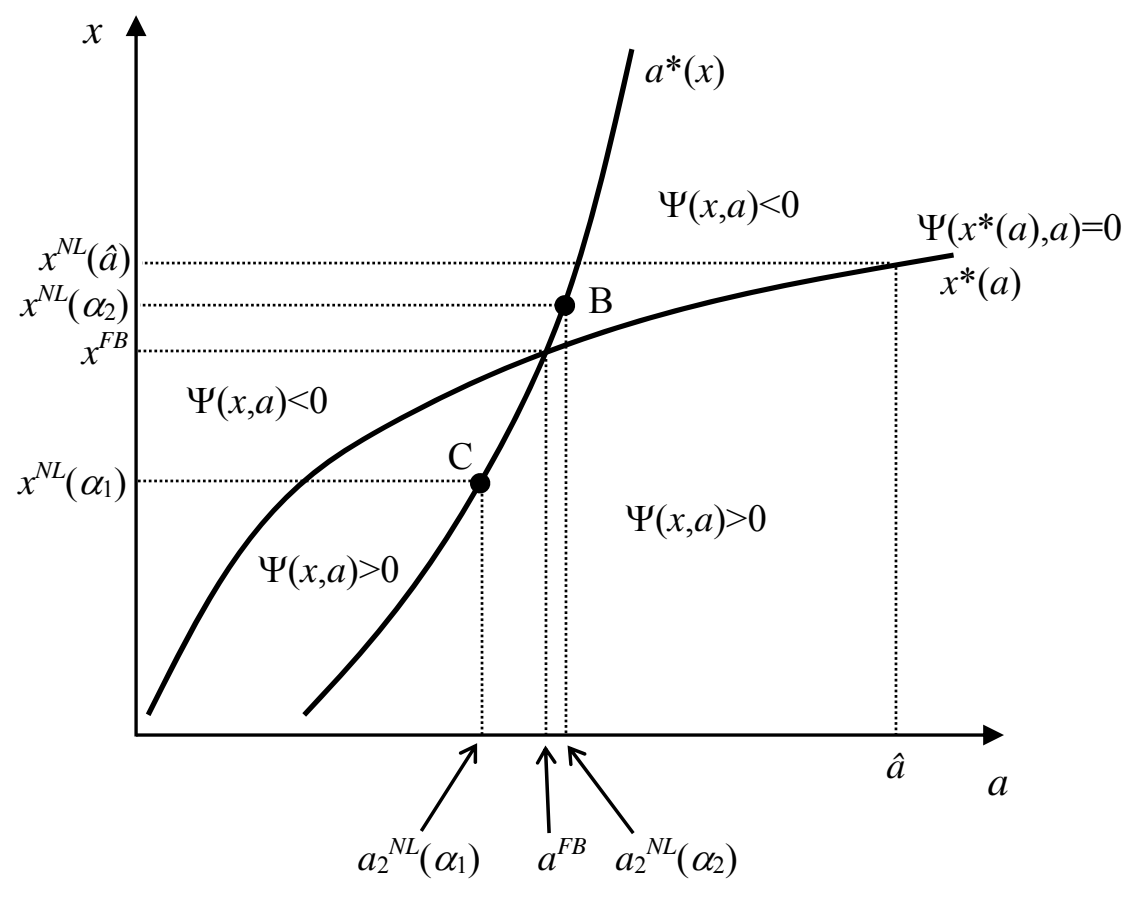

Notes: $\quad a_{2}{ }^{N L}(\alpha)=a^{*}\left(x^{N L}(\alpha)\right), \quad x^{F B}=x^{N L}(1), \quad a^{F B}=a_{1}{ }^{N L}(1)=a_{2}{ }^{N L}(1), \quad$ and $\quad a^{*}(x) \equiv a^{*}(x, 1)$. The figure assumes $\alpha_{2}>1>\alpha_{1}$. 
Figure B1: Ex-post net consumer utility under negligence for $x^{N G} \neq X^{F B}$

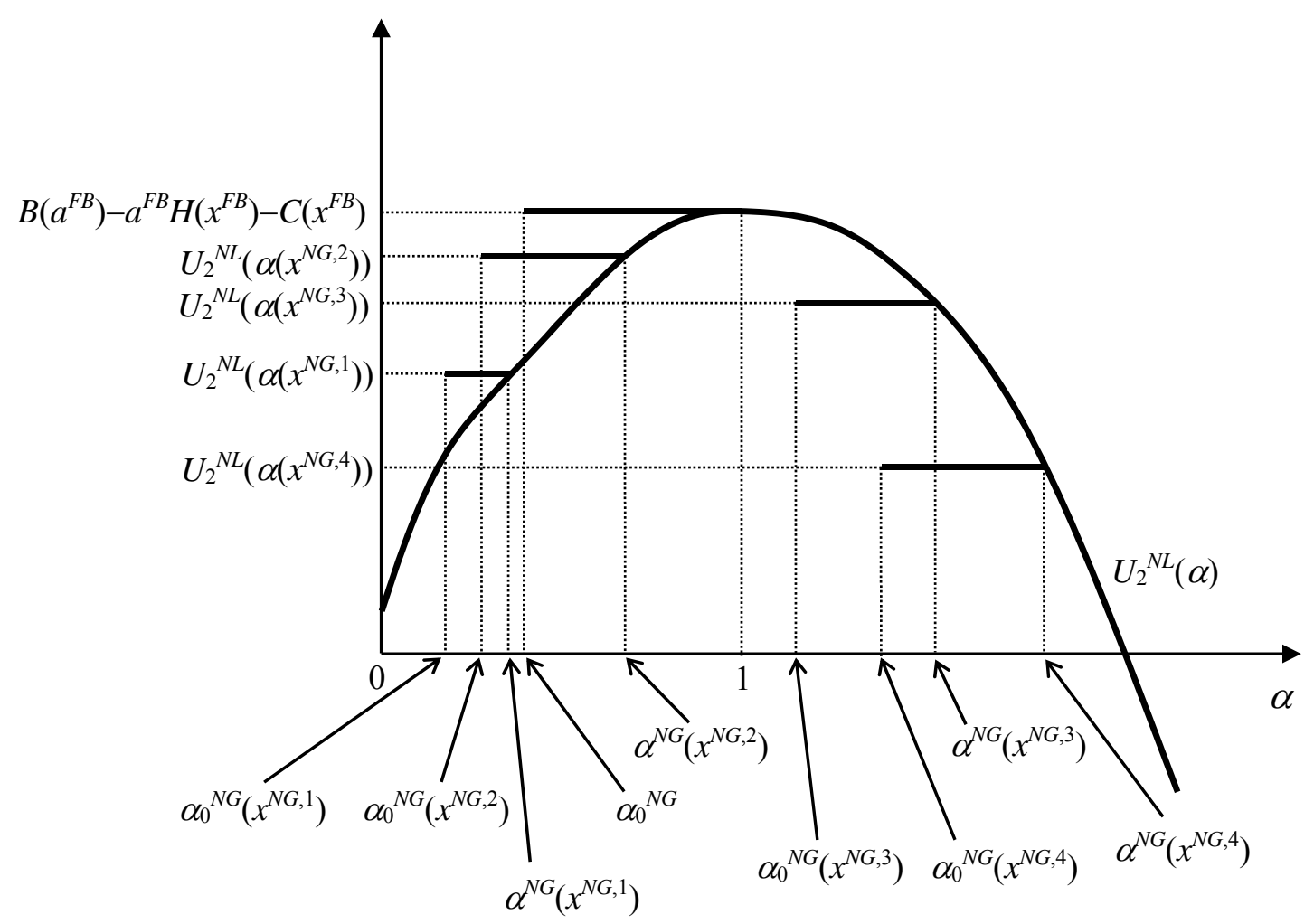

Notes: $U_{2}{ }^{N L}(1)=U_{2}{ }^{N L}\left(\alpha\left(x^{F B}\right)\right)=B\left(a^{F B}\right)-a^{F B} H\left(x^{F B}\right)-C\left(x^{F B}\right), \quad \alpha_{0}{ }^{N G} \equiv \alpha_{0}^{N G}\left(x^{F B}\right), \alpha^{N G}\left(x^{F B}\right)=1$. The figure assumes $x^{N G, 1}<\chi^{N G, 2}<\chi^{F B}<\chi^{N G, 3}<\chi^{N G, 4}$. 